\title{
DNA Extraction and Host Depletion Methods Significantly Impact and Potentially Bias Bacterial Detection in a Biological Fluid
}

\author{
(D) Erika Ganda, a,b* (D) Kristen L. Beck, ${ }^{\mathrm{b}, \mathrm{c}}$ (D) Niina Haiminen,, (1D) Justin D. Silverman, ${ }^{\mathrm{e}, \mathrm{f}, \mathrm{g}}$ Ban Kawas, ${ }^{\mathrm{b}, \mathrm{c}}$ (D) Brittany D. Cronk, \\ Renee R. Anderson, ${ }^{\text {h }}$ (D) Laura B. Goodman, ${ }^{\text {h }}$ (D) Martin Wiedmanna,b \\ aDepartment of Food Science, Cornell University, Ithaca, New York, USA \\ ${ }^{b}$ Consortium for Sequencing the Food Supply Chain, San Jose, California, USA \\ IBM Almaden Research Center, San Jose, California, USA \\ d|BM T.J. Watson Research Center, Yorktown Heights, New York, USA \\ eCollege of Information Sciences and Technology, Penn State University, University Park, Pennsylvania, USA \\ fDepartment of Statistics, Penn State University, University Park, Pennsylvania, USA \\ gDepartment of Medicine, Penn State College of Medicine, Hershey, Pennsylvania, USA \\ hDepartment of Population Medicine and Diagnostic Sciences, College of Veterinary Medicine, Cornell University, Ithaca, New York, USA
}

ABSTRACT Untargeted sequencing of nucleic acids present in food can inform the detection of food safety and origin, as well as product tampering and mislabeling issues. The application of such technologies to food analysis may reveal valuable insights that are simply unobtainable by targeted testing, leading to the efforts of applying such technologies in the food industry. However, before these approaches can be applied, it is imperative to verify that the most appropriate methods are used at every step of the process: gathering of primary material, laboratory methods, data analysis, and interpretation. The focus of this study is on gathering the primary material, in this case, DNA. We used bovine milk as a model to (i) evaluate commercially available kits for their ability to extract nucleic acids from inoculated bovine milk, (ii) evaluate host DNA depletion methods for use with milk, and (iii) develop and evaluate a selective lysis-propidium monoazide (PMA)-based protocol for host DNA depletion in milk. Our results suggest that magnetically based nucleic acid extraction methods are best for nucleic acid isolation of bovine milk. Removal of host DNA remains a challenge for untargeted sequencing of milk, highlighting the finding that the individual matrix characteristics should always be considered in food testing. Some reported methods introduce bias against specific types of microbes, which may be particularly problematic in food safety, where the detection of Gram-negative pathogens and hygiene indicators is essential. Continuous efforts are needed to develop and validate new approaches for untargeted metagenomics in samples with large amounts of DNA from a single host.

IMPORTANCE Tracking the bacterial communities present in our food has the potential to inform food safety and product origin. To do so, the entire genetic material present in a sample is extracted using chemical methods or commercially available kits and sequenced using next-generation platforms to provide a snapshot of the microbial composition. Because the genetic material of higher organisms present in food (e.g., cow in milk or beef, wheat in flour) is around 1,000 times larger than the bacterial content, challenges exist in gathering the information of interest. Additionally, specific bacterial characteristics can make them easier or harder to detect, adding another layer of complexity to this issue. In this study, we demonstrate the impact of using different methods for the ability to detect specific bacteria and highlight the
Citation Ganda E, Beck KL, Haiminen N, Silverman JD, Kawas B, Cronk BD, Anderson RR, Goodman LB, Wiedmann M. 2021. DNA extraction and host depletion methods significantly impact and potentially bias bacterial detection in a biological fluid. mSystems 6:e00619-21. https://doi.org/10 .1128/mSystems.00619-21.

Editor Sean M. Gibbons, Institute for Systems Biology

Copyright $\odot 2021$ Ganda et al. This is an open access article distributed under the terms of the Creative Commons Attribution 4.0 International license.

Address correspondence to Erika Ganda, ganda@psu.edu.

* Present address: Erika Ganda, Department of Animal Science, The Pennsylvania State University, State College, Pennsylvania, USA

3 It all depends: on your sample type and objectives! DNA extraction methods significantly impact and potentially bias bacterial detection in a biological fluid.

Received 20 May 2021

Accepted 21 May 2021

Published 15 June 2021 
need to ensure that the most appropriate methods are being used for each particular sample.

KEYWORDS host depletion, shotgun metagenomics, milk, DNA, RNA, biases, propidium monoazide, dairy, low biomass, food microbiome

$\mathrm{n}$ the past decade, recent developments in molecular methods, including highthroughput sequencing (HTS) technologies, have demonstrated the feasibility of sequencing-based analysis of various foods and food-associated environments and the potential for application in informing food safety practices (1), product processing methods (2), and ingredient authentication $(3,4)$. This has spurred the efforts to translate the use of such technologies to the industry setting, with the objective of moving food safety testing to the next frontier (5). However, before such refined approaches can be reliably applied in the industry, it is imperative that appropriate methods be employed at every step of the process: gathering of primary material, laboratory methods, data analysis, and interpretation. In this study, we highlight the importance of considering the food matrix characteristics as well as the laboratory methodologies applied. Bovine milk is used as a model to demonstrate the several challenges associated with developing HTS methods for use in food matrices.

Like many other foods, milk is a chemically complex biological fluid. Milk contains several compounds that can hamper the chemistry involved in DNA and RNA extraction $(6,7)$ and act as PCR inhibitors, such as calcium ions, fats, and proteins $(8,9)$. Additionally, lactoferrin, an enzyme present in bovine milk, has recently been described to have both DNase and RNase activity (10). Another challenge for untargeted sequencing applications of bovine milk is the presence of bovine somatic cells. The bovine genome is 1,000 times larger than an average bacterial genome (bovine, 2.7 $\mathrm{Gb}$; bacteria, 3.6 $\mathrm{Mb}$ [average], 3.4 Mb [median] [11, 12]). Thus, even when present in much smaller amounts than bacterial cells, bovine somatic cells introduce an enormous quantity of typically unwanted host nucleic acids in untargeted HTS studies. Realistically, however, high-quality raw milk may contain around 200,000 bovine somatic cells and 20,000 or fewer bacterial cells per $\mathrm{ml}$ (13), leading to a 10,000-fold higher abundance of bovine than bacterial DNA in high-quality raw milk.

Despite the challenges associated with nucleic acid extraction from milk and the amount of host DNA present, several investigations have successfully used milk (14-16) or other dairy products (17) as their sample of interest in targeted and untargeted HTS studies, highlighting the potential for application of HTS technologies in food production settings. Total RNA sequencing can be more informative than untargeted DNA sequencing, as it has the potential to provide gene expression (e.g., toxin production) in addition to taxonomic relative abundance in a community of food-associated microorganisms $(4,18)$. Compared to DNA extraction, RNA extraction is a more complex and challenging process, given the short half-life of RNA compared to that of DNA, its inherent susceptibility to degradation, and the known presence of RNases in milk (10). Nevertheless, a number of studies have been successful in extracting RNA from dairy products, highlighting the potential of RNA-based techniques for food safety and quality surveillance (19-21).

When the ultimate objective is to use HTS to create a tool that can be used to inform food safety and quality in industry settings, understanding the impact and biases introduced by using protocols that have not yet been tested or optimized for a given food matrix is of great importance. In addition, to be potentially adopted in industry settings, laboratory protocols should be performed in a timely manner. It is important to characterize the entire food sample, and most protocols available for nucleic acid extraction in milk begin with centrifugation and fat removal steps, which can in themselves introduce significant bias to the final result. For example, bacterial spores have been described to aggregate in the fat layer of milk samples subjected to gravity separation $(22,23)$, and RNA yields have been shown to vary among different 
milk fractions (24). Unfortunately, these potential introductions of bias are overlooked in most investigations.

While a number of studies have investigated commercially available protocols for nucleic acid extraction of milk in terms of DNA concentration, quality, and ability to detect specific pathogens (25-27), their main objective was not the assessment of differential DNA extraction or biases in the representation of diverse bacterial populations, which would require the inclusion of mock bacterial communities of interest in a milk sample and comparison of several protocols.

Host DNA contamination is a challenge not exclusive to milk and other food samples, as mammalian DNA has been shown to dominate the number of sequencing reads in cerebrospinal fluid, skin, vaginal, and oral metagenomes in humans (28-30). To tackle the host DNA issue, enzymatic and immunomagnetic protocols aimed at decreasing host DNA contamination became commercially available and have been tested in select sample types $(28,29,31)$. In addition, a number of "homebrew" methods have been tested to allow for successful depletion of host DNA $(28,32,33)$. Nevertheless, these methods are not guaranteed to work with every sample type, and to the best of our knowledge, no host DNA depletion methods have been evaluated for their applicability in milk.

The goals of this study were (i) to evaluate commercially available kits for their ability to extract nucleic acids (e.g., DNA and RNA) from bovine milk, (ii) to evaluate host DNA depletion methods for use with bovine milk, and (iii) to develop and evaluate a selective lysis-propidium monoazide (PMA)-based protocol for host DNA depletion in milk. Our overarching hypothesis was that methodologies would differ with regard to the efficacy of nucleic acid extraction, and potential biases would be observed. Experiments were thus performed on raw bovine milk inoculated with mock bacterial communities, which included Gram-negative (Salmonella enterica), Gram-positive (Listeria monocytogenes), and mycobacterial (Mycobacterium smegmatis) organisms, as well as spores representing aerobic sporeformers (Bacillus wiedmannii).

\section{RESULTS}

The extraction method significantly impacts bacterial quantification through qPCR. We assessed seven commercially available DNA extraction methods for their ability to isolate DNA from milk samples inoculated with a mock bacterial community (Fig. 1A) (for milk sample characteristics, see Table S1 in the supplemental material). Nucleic acid quantification and quality measurements (Table S2) need to be interpreted with caution due to the low overall DNA yield ( $<10 \mathrm{ng} / \mu \mathrm{l}$ for all samples), which placed readings below the linear range for most samples as measured via fluorescence with a Nanodrop. We were able to measure DNA for all kits via fluorescence with a high-sensitivity set of reagents, and all kits yielded sufficient DNA to allow for quantitative PCR (qPCR)-based quantification of the members of the bacterial mock community (i.e., Bacillus wiedmannii, Listeria monocytogenes, Mycobacterium smegmatis, and Salmonella sp.) as well as total bacterial 16S rRNA gene copies and bovine DNA.

The failure rates varied across kits (Table 1; Fig. 2), with the MagAttract mastitis kit having no failed reactions and the MagMAX CORE nucleic acid purification kit having only one failed reaction in the total-bacteria assay. From the column-based methods, the E.Z.N.A Food DNA (EZFood) kit had the largest number of failed reactions, with a total of 30 failed reactions across five assays (all except for bovine DNA); because of this, we could not include data from this method in any of our statistical models, as this would have caused nonidentifiability. The Power Soil Pro (PSoilP) kit had 5 failed reactions in the Listeria and Salmonella assays, the Power Food (PFood) kit had only one failed reaction in the Bacillus assay, and the ZymoBIOMICS DNA/RNA (ZymoDNA or ZymoRNA) minikit had no failures. Interestingly, the AllPrep PowerViral DNA/RNA (PowerViralDNA or PowerViralRNA) kit had all reactions in the first biological replicate fail for the Listeria assay. As a result, we could not compare the PowerViral method to other methods in the Listeria assay.

Of reactions that did not fail, the two magnet-based DNA extraction methods (the CORE and MagAttract mastitis kits, the two leftmost methods in Fig. 2) always yielded 


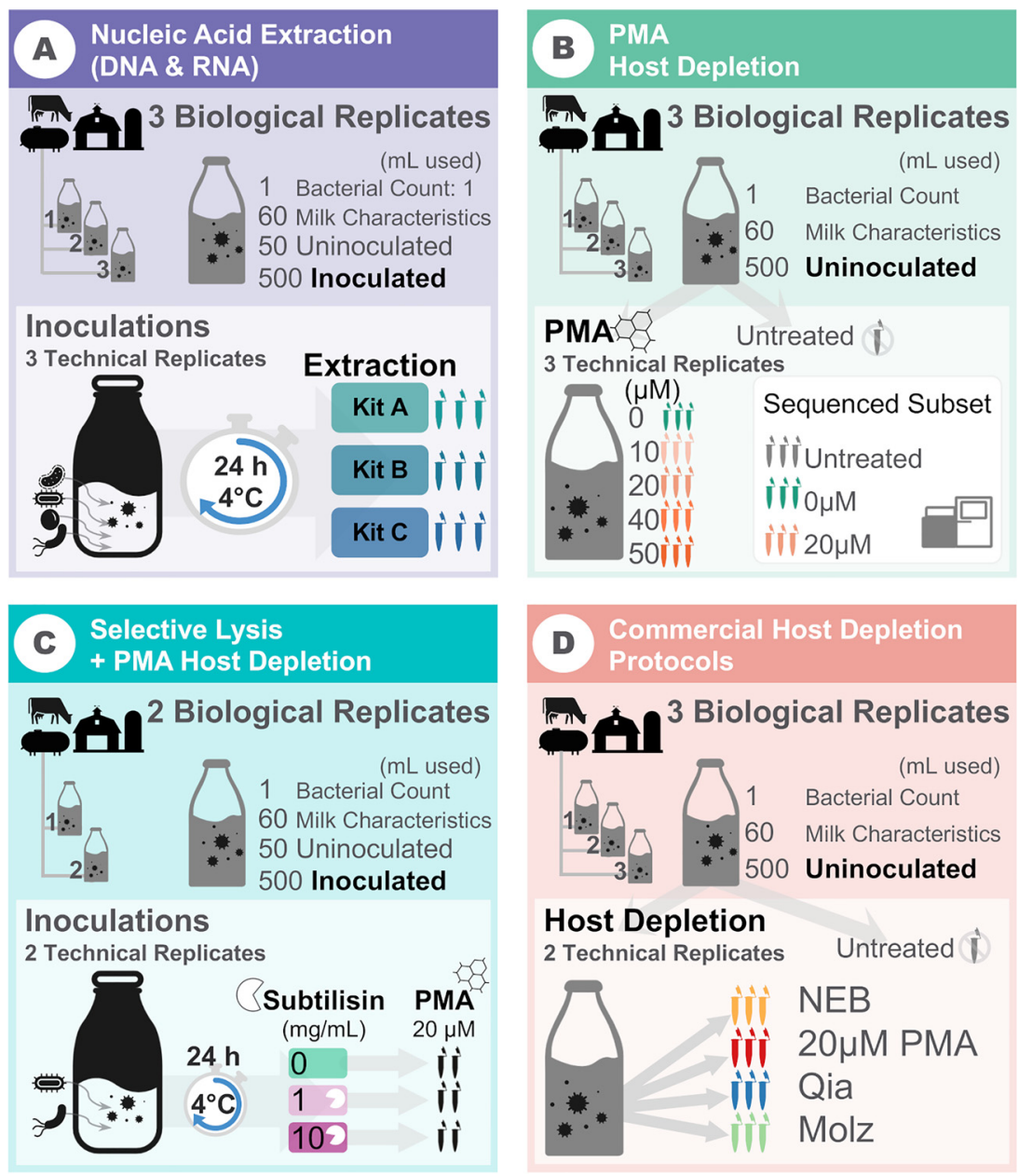

FIG 1 Study overview. Each panel depicts the design for each aspect evaluated, with respective numbers of biological and technical replicates. The qPCR assays were performed in duplicate for each experimental replicate. Copy numbers were calculated for bovine DNA, total 16S rRNA genes, Bacillus, Listeria, Mycobacterium, and Salmonella (A); bovine DNA, total 16S rRNA genes, Listeria, and Salmonella (C); and only bovine DNA and total 16S rRNA genes (B and D) because no inoculation was performed.

numerically higher log copy numbers (for all members of the mock community and for total bacterial $16 \mathrm{~S}$ rRNA genes) than the other five kits. Bacterial copy numbers for the two magnet-based kits also had lower variability between technical replicates than column-based kits, with the E.Z.N.A Food DNA kit showing particularly large variability between technical replicates; DNA yields for this kit were also so low that no qPCR amplification was observed in the L. monocytogenes qPCR targeting rpoB.

Among the column-based extraction methods, Power Food, PowerViral, and Zymo were comparable with regard to (i) their ability to recover DNA of the members of the

TABLE 1 Descriptive statistics of log numbers of copies per milliliter of milk for DNA extraction

\begin{tabular}{|c|c|c|c|c|c|c|c|}
\hline Organism & \multicolumn{7}{|c|}{ Mean $\log _{10}$ no. of copies per $\mathrm{ml}$ of milk as detected via qPCR (SD), no. of expts, no. of failures } \\
\hline Total bacterial DNA & $7.51(0.54), 18,^{0}$ & $6.99(0.96), 18,{ }^{1}$ & $4.30(1.72), 12,^{2}$ & $6.71(0.57), 18,^{0}$ & $6.31(0.48), 18,^{0}$ & $6.96(0.59), 18,^{0}$ & $6.78(0.40), 18,^{0}$ \\
\hline Listeria monocytogenes & $6.58(0.48), 18,^{0}$ & $6.21(0.89), 18,{ }^{0}$ & $\mathrm{NA}(\mathrm{NA})^{a}, 12,12$ & $5.93(0.49), 18,^{0}$ & $5.46(0.68), 18,^{3}$ & $6.84(0.09), 18,{ }^{6}$ & $6.00(0.59), 18,{ }^{0}$ \\
\hline Mycobacterium smegmatis & $6.70(0.42)$, & $6.81(0.31), 18,{ }^{0}$ & $3.97(1.39), 12,^{7}$ & $6.29(0.34), 18,^{0}$ & $5.44(0.82), 18,^{0}$ & $6.25(0.38), 18,{ }^{0}$ & $6.30(0.58), 18,^{0}$ \\
\hline Salmonella sp. & $5.80(0.61), 18,^{0}$ & $6.07(0.26), 18,0$ & $3.83(1.12), 12,5$ & $5.24(0.72), 18,^{0}$ & $4.13(0.77), 18^{2}$ & $5.77(0.19), 18,^{0}$ & $5.34(0.61), 18,^{0}$ \\
\hline Bovine DNA & $5.37(0.05), 18,^{0}$ & $5.45(0.08), 18,0$ & $4.71(0.59), 12,^{0}$ & $4.86(0.08), 18,^{0}$ & $4.05(0.24), 18,^{0}$ & $5.20(0.11), 18,^{0}$ & $4.81(0.06), 18,^{0}$ \\
\hline
\end{tabular}

${ }^{a} \mathrm{NA}$, not applicable (this method did not yield detectable signal in qPCR for Listeria monocytogenes). 
Bovine

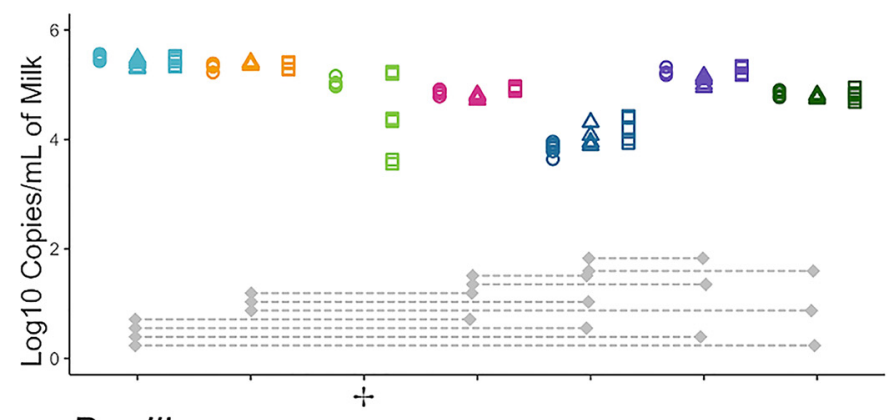

Bacillus
Total Bacteria

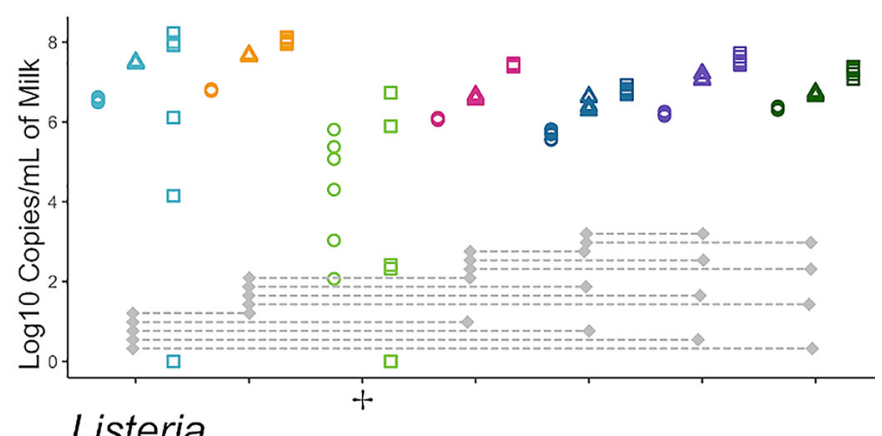

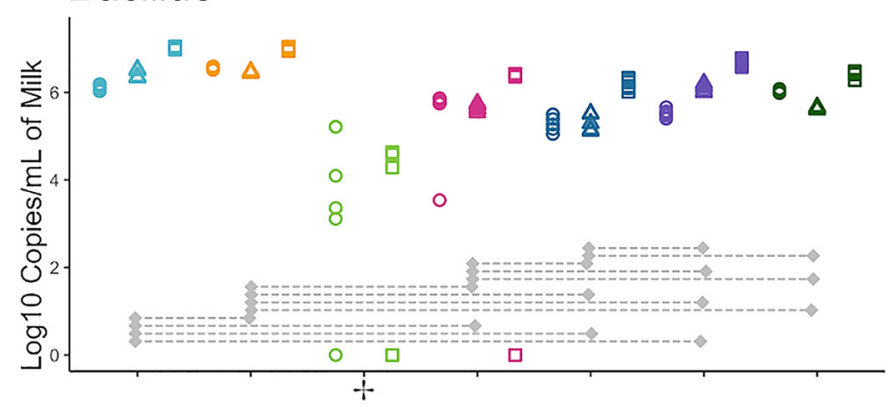

Mycobacterium
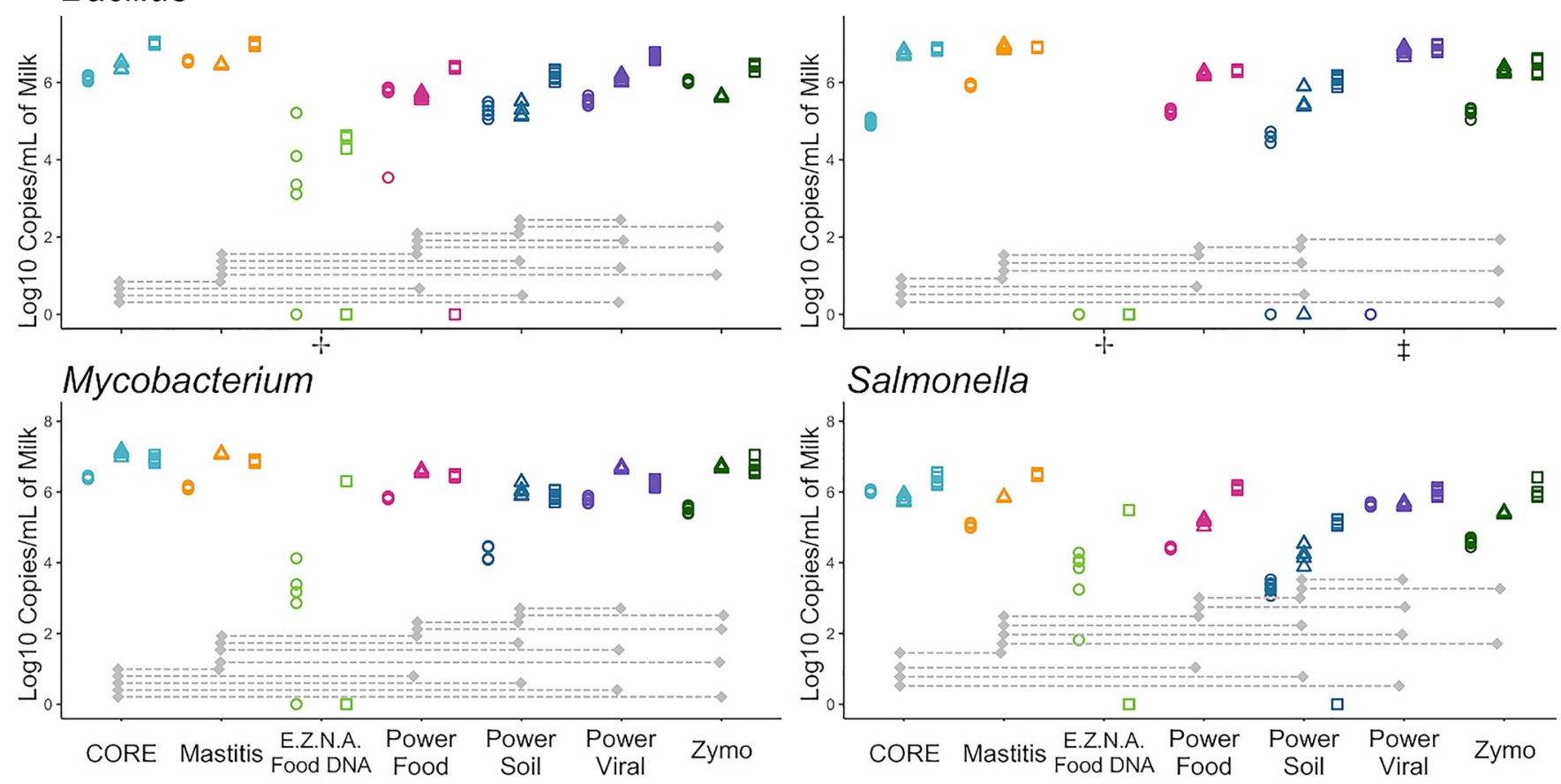

Salmonella

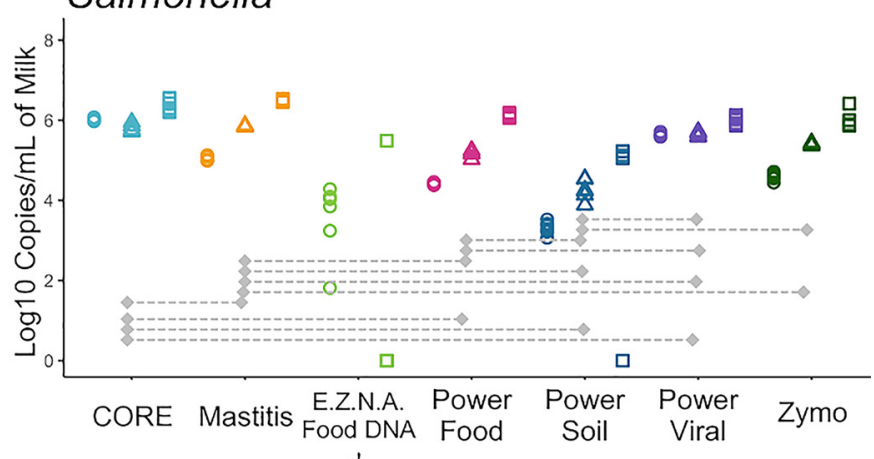

Extraction Kit

FIG 2 Scatterplots of normalized log copy numbers per milliliter of milk obtained with different DNA extraction kits. Points at 0 log copy numbers are graphical demonstrations of failed reactions. Gray bars represent pairwise significant differences at the 0.05 level after Bonferroni multiple-comparison adjustment within and between linear models, which included extraction kit, biological replicate, and their interactions. Scatterplot shapes represent each of three independent biological replicates (circles, first; triangles, second; and squares, third), whereas colors represent kits evaluated. Each panel depicts results of a single gene target evaluated. +, E.Z.N.A. Food DNA was not included in the second biological replicate and was excluded from all linear models; ‡ PowerViral was not included in the linear model for Listeria.

mock community and (ii) variability within technical replicates (Fig. 2; Table 1 provides detailed descriptive statistics). The Power Soil Pro kit (another column-based kit) generally provided lower bacterial DNA yields for each member of the mock community than these three kits.

We also evaluated the ability to isolate bacterial RNA for (i) two kits designed for isolation of RNA only and for (ii) three kits designed for isolation of both RNA and DNA (Table 2). As with the DNA detection data detailed above, all kits yielded very low total nucleic acid concentrations based on spectrophotometry. Reverse transcriptase qPCR (RT-qPCR) amplification of gene targets for Salmonella sp. and L. monocytogenes as well as bovine RNA did not yield amplification from samples treated with DNase (these initial tests were performed on two technical replicates for each of the four kits). Control amplifications on nucleic acids before DNase treatment, however, yielded amplification with cycle threshold (CT) values that did not differ between the RT-qPCR and the control qPCR targeting DNA, suggesting the presence of residual 
TABLE 2 Nucleic acid extraction kit characteristics

\begin{tabular}{|c|c|c|c|c|c|c|c|c|}
\hline Abbreviation(s) & Kit & $\begin{array}{l}\text { Sample } \\
\text { input }(\mu \mathrm{l})\end{array}$ & $\begin{array}{l}\text { Nucleic acid } \\
\text { output }(\mu l)\end{array}$ & $\begin{array}{l}\text { Nucleic } \\
\text { acid }\end{array}$ & Processing & Capture & $\begin{array}{l}\text { Catalog } \\
\text { no. }\end{array}$ & Manufacturer \\
\hline $\begin{array}{c}\text { PowerViralDNA or } \\
\text { PowerViralRNA }\end{array}$ & AllPrep PowerViral DNA/RNA kit & 200 & 100 & DNA/RNA & Manual & Column based & $28000-50$ & Qiagen \\
\hline ZymoDNA, ZymoRNA & ZymoBIOMICS DNA/RNA minikit & 250 & 100 & DNA/RNA & Manual & Column based & R2002 & Zymo \\
\hline Mastitis & MagAttract mastitis kit & 400 & 100 & DNA & Automated & Magnet based & 947757 & Qiagen \\
\hline EZFood & E.Z.N.A. Food DNA kit & 500 & 100 & DNA & Manual & Column based & D4616-00 & Omega \\
\hline RNeasy & RNeasy Protect Bacteria minikit & 1,500 & 50 & RNA & Manual & Column based & 74524 & Qiagen \\
\hline EZNARNA & E.Z.N.A. HP total RNA kit & 500 & 50 & RNA & Manual & Column based & R6812-00 & Omega \\
\hline
\end{tabular}

DNA in the extracted nucleic acids and demonstrating that, by following the protocols described here, we were not able to successfully isolate RNA from our milk samples.

Osmotic lysis followed by PMA treatment decreases host DNA but also impacts bacterial DNA. We compared protocols that combined osmotic lysis and treatment with multiple concentrations of PMA for their ability to reduce host DNA, compared to bacterial DNA copy numbers. To assess whether osmotic lysis alone impacted copy numbers, we compared untreated control (UTC) samples to samples that underwent centrifugation and osmotic lysis with double-distilled water $\left(\mathrm{ddH}_{2} \mathrm{O}\right)$ but without PMA addition (0 $\mu$ M PMA); this comparison revealed significantly lower bovine and bacterial DNA copy numbers in $0 \mu \mathrm{M}$ PMA samples, suggesting significant effects of sample processing (including lysis) independent of PMA addition (Fig. 3, UTC versus $0 \mu \mathrm{M}$ comparisons). We also observed that PMA concentration significantly impacted bovine and bacterial DNA copy numbers in a dose-dependent manner; as the PMA concentration increased, a sharp decrease was observed in bovine copy numbers, whereas a less pronounced, but still noticeable, decrease was observed in bacterial copy numbers (Fig. 3). This trend was confirmed in the model estimates, which showed a significant and negative effect of PMA in both linear models, with a greater estimate for bovine copy numbers $(-0.022)$ than for bacterial copy numbers (-0.012). Treatment with $20 \mu \mathrm{M}$ PMA was the concentration deemed optimal, as it yielded the greatest decrease in host DNA without critically compromising bacterial DNA recovery and thus was chosen for subsequent comparisons with commercially available host DNA depletion protocols.

We also selected a small subset of milk samples from each of the three biological replicates to undergo deep untargeted sequencing, including one sample each of the three biological replicates representing (i) untreated samples, (ii) samples treated with $20 \mu \mathrm{M}$ PMA, and (iii) samples that underwent osmotic lysis but were not treated with PMA (they underwent centrifugation and selective lysis with $\mathrm{dd}_{2} \mathrm{O}$ but were not treated with PMA), which were included to allow us to determine if differences observed would be due to PMA treatment or sample processing prior to PMA addition.

Sequencing had an average read depth of 51,563,707 reads per sample (range, $25,488,728$ to $127,203,413$ reads). Overall, less than $1 \%$ of all reads that passed quality control $(\mathrm{QC})$ were determined to be of microbial origin regardless of PMA treatment (Table 3; Fig. 4), and around 3\% remained unclassified.

While we observed a pronounced increase in the number of bacterial reads per 1 million sequenced reads with the PMA treatment (Fig. 5A), attempting to deplete host DNA with PMA also appeared to influence the resulting microbial profiles of samples, leading to visible differences between replicates of the same biological samples (Fig. 5B). For example, PMA treatment of sample Bio1 resulted in greater relative abundances of Cutibacterium organisms than occurred in aliquots of the same sample (Bio1) that were not treated (UTC) or underwent selective lysis with $\mathrm{dd}_{2} \mathrm{O}$ but received no PMA treatment $(0 \mu \mathrm{M})$. Similar differences between the UTC and the $0 \mu \mathrm{M}$ and $20 \mu \mathrm{M}$ 

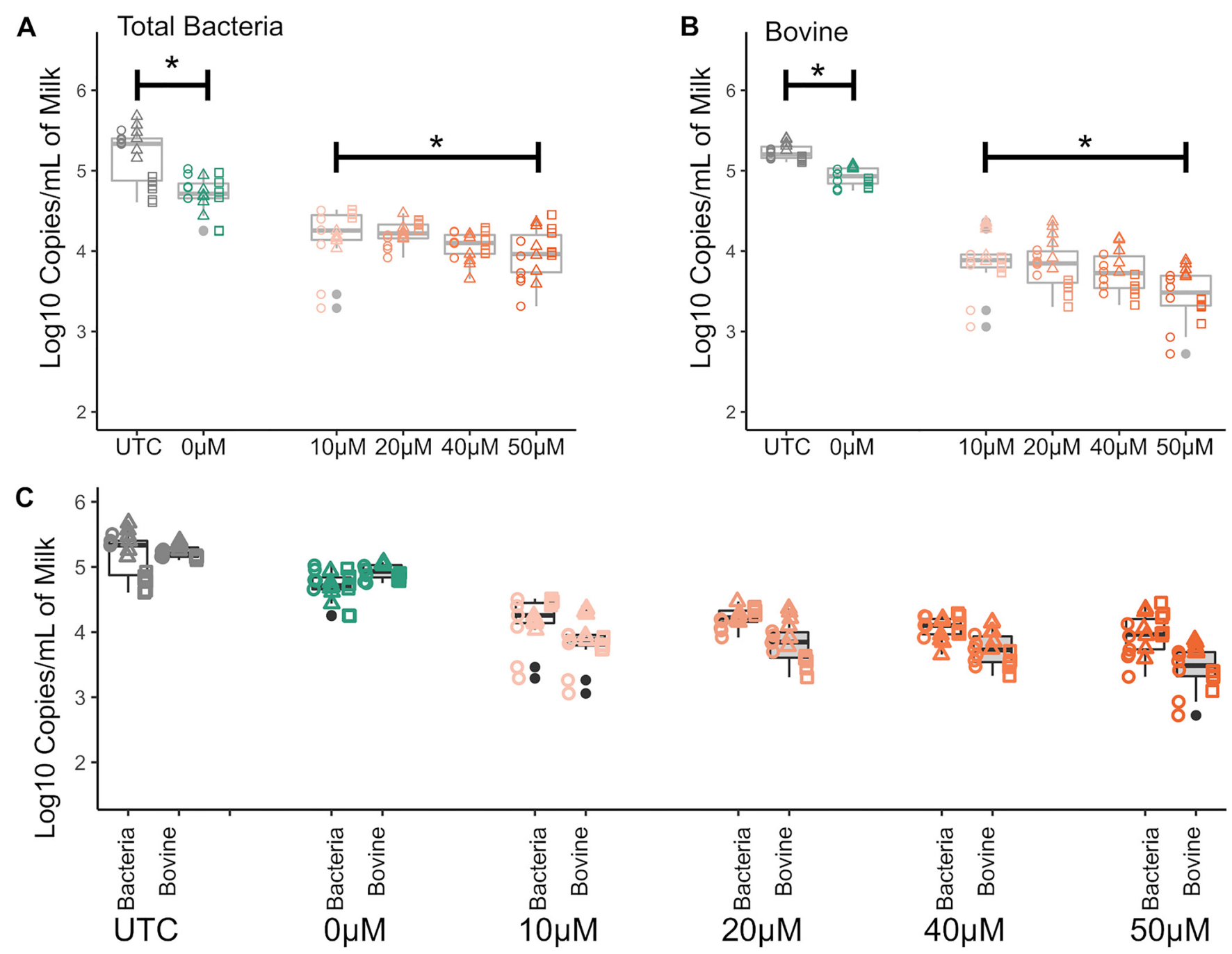

UTC

$0 \mu \mathrm{M}$
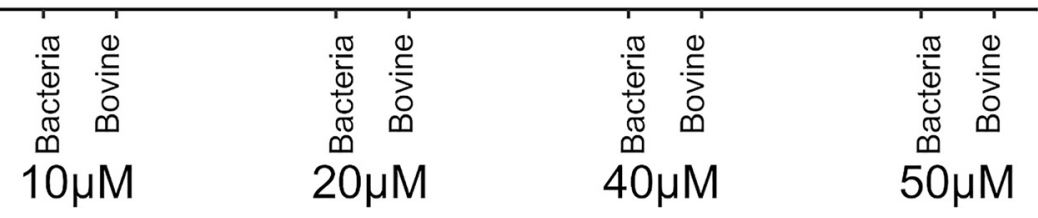

\section{PMA Concentration}

FIG 3 Effect of osmotic lysis of raw milk followed by treatment with various PMA concentrations on host and bacterial DNA counts as determined by qPCR. Boxplots represent normalized log copy numbers per milliliter of milk. UTC, untreated control sample; $0 \mu \mathrm{M}$, milk that underwent osmotic lysis but was not treated with PMA. Scatterplot shapes represent each of three independent biological replicates (circles, first; triangles, second; and squares, third), whereas colors represent concentrations evaluated. Asterisks represent significant differences at a $P$ of $<0.05$ in linear-model comparisons. Osmotic lysis significantly decreases $\log _{10}$ copy numbers in non-PMA-treated samples (UTC versus $0 \mu \mathrm{M}$ ), and increasing PMA concentrations significantly decrease log ${ }_{10}$ copy numbers in a dose-dependent manner.

PMA samples were observed for the other two samples sequenced (Bio2 and Bio3)

(Fig. 5B).

Host depletion methods successfully decrease host DNA but not to the extent needed to make a significant impact for use in milk sequencing studies. We compared the results of host DNA depletion methods and osmotic lysis followed by PMA treatment in three independent biological replicates. In each biological replicate, a freshly collected milk sample was homogenized and divided into five separate aliquots that were processed in parallel for each of the five methods (e.g., PMA method, Molzym [Molz] kit, NEBNext microbiome DNA enrichment [NEB] kit, QIAamp DNA microbiome [Qia] kit, and untreated control [UTC]). The means by which host DNA depletion was accomplished varied between methods; some kits depended on host DNA degradation followed by treatment with different enzymes (e.g., Qiagen and Molzym kits), while the NEB kit was based on the capture of methylated host DNA (for details on kits and methods, see Table 4; for descriptive statistics, see Table 5). Overall, host DNA removal treatments significantly decreased bovine copy numbers compared 
TABLE 3 Descriptive statistics of shotgun metagenomics sequencing results assessing the effect of PMA treatment

\begin{tabular}{llll}
\hline & \multicolumn{2}{l}{ Mean \% (SD), no. of expts ${ }^{b}$} \\
\cline { 2 - 4 } Parameter $^{a}$ & No treatment & 0 $\boldsymbol{\mu}$ M PMA (wash only) & 20 $\boldsymbol{\mu M}$ PMA \\
\hline Bovine & $93.87(0.54), 3$ & $93.83(0.366), 3$ & $92.46(0.866), 3$ \\
Microbial & $0.010(0.002), 3$ & $0.011(0.005), 3$ & $0.109(0.027), 3$ \\
Unclassified & $2.933(0.122), 3$ & $3.066(0.04), 3$ & $3.113(0.11), 3$ \\
Low quality (QC filtered) & $3.18(0.441), 3$ & $3.09(0.384), 3$ & $4.31(0.851), 3$ \\
\hline
\end{tabular}

andicates to which class (e.g., eukaryotic, bacterial, viral, archaeal) sequencing reads were assigned using methods described in the work of Beck et al. (4).

${ }^{b}$ The average numbers of input reads were $67,983,431,45,846,439$, and 40,861 for the no-treatment, $0 \mu \mathrm{M} \mathrm{PMA}$ and $20 \mu \mathrm{M}$ PMA experiments, respectively.

to those of an untreated control (Fig. 6B) $(P<0.001)$. However, we also observed a significant loss of bacterial copy numbers across methods (Fig. 6A) $(P<0.001)$. Notably, the Molzym kit caused the largest reduction of both bovine and bacterial DNA copy numbers, to levels that likely would be insufficient as inputs for shotgun metagenomic sequencing. Treatment of raw milk with Molzym reagents specifically resulted in a pellet that was challenging to bring back to solution, which likely led to considerable nucleic acid losses and renders this method unreliable for use with milk.

As all host DNA depletion methods also led to the depletion of bacterial DNA, we chose to use the calculated log difference between bovine and bacterial DNA copy numbers as key metrics for evaluating the different host DNA depletion methods. Untreated samples showed an average of 0.77 -log-higher bacterial DNA copy numbers than bovine DNA copy numbers (Fig. 6C). By comparison, the log difference after different host depletion methods ranged from $1.22 \log$ (PMA method) to 2.09 log (Molzym kit). If treated samples underwent untargeted sequencing, this decrease in bovine copies would translate into negligible differences in terms of relative abundances of bacterial reads versus bovine reads given the approximately thousandfold difference between the bovine genome size and the average bacterial genome sizes.

Enzymatic selective lysis of inoculated milk followed by PMA treatment differentially affects detection of Gram-positive and Gram-negative bacteria through qPCR. In a final attempt to optimize a host depletion protocol that would be
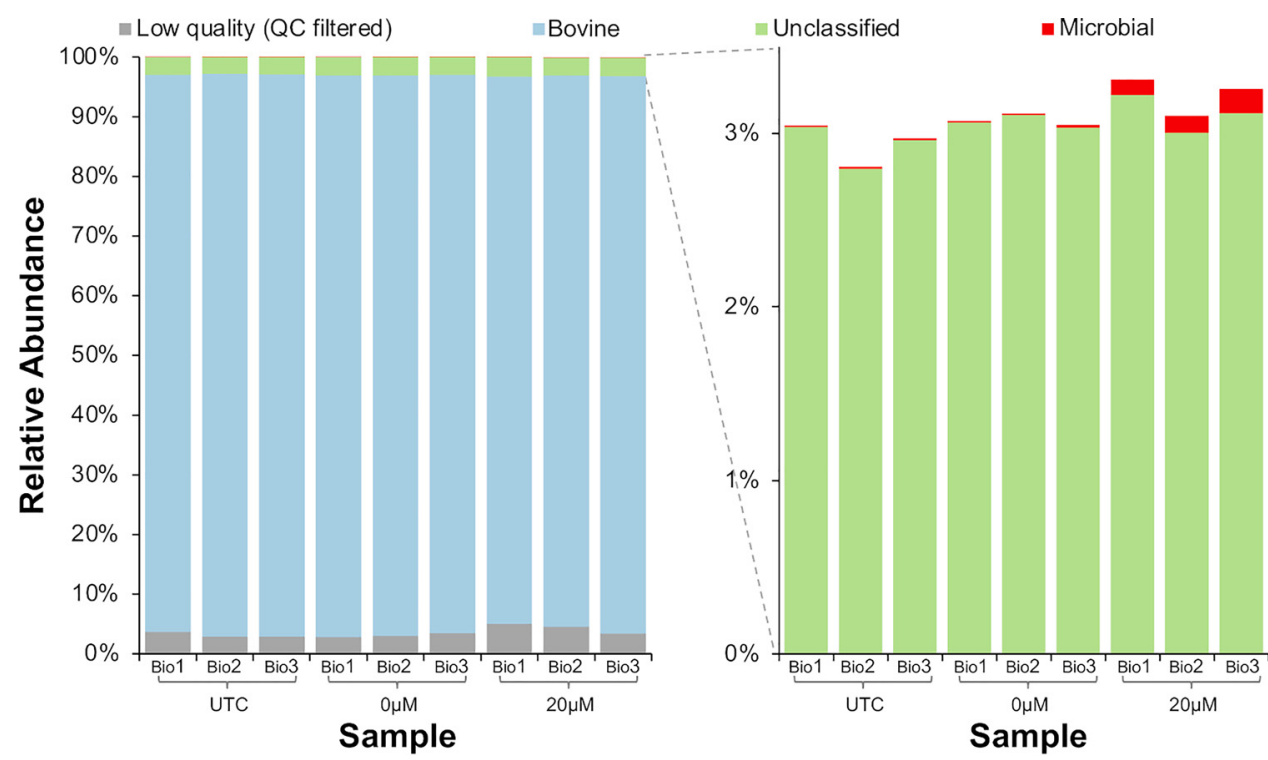

FIG 4 Effect of host DNA depletion with PMA on the percentage of sequencing reads assigned to the bovine genome or microbial genomes. Raw milk was collected on three separate days and divided into aliquots that underwent each of the processing methods. UTC, untreated control sample; $0 \mu \mathrm{M}$, milk that underwent osmotic lysis but was not treated with PMA; $20 \mu \mathrm{M}$, milk that underwent osmotic lysis and PMA treatment at $20 \mu \mathrm{M}$. 


\begin{tabular}{|c|c|c|c|c|c|c|}
\hline $\begin{array}{l}\text { Escherichia } \\
\text { Lactococcus } \\
\text { Coxiella } \\
\text { Pseudomonas }\end{array}$ & $\begin{array}{l}\text { Cutibacterium } \\
\text { Salmonella } \\
\text { Propionibacterium } \\
\text { Fusobacterium }\end{array}$ & $\begin{array}{l}\text { Strepto coccus } \\
\text { Coryne bacterium } \\
\text { Lacto bacillus } \\
\text { Leptotrichia }\end{array}$ & $\begin{array}{l}\text { Klebsiella } \\
\text { Enterobacter } \\
\text { Bifidobacterium } \\
\text { Micrococcus }\end{array}$ & $\begin{array}{l}\square \text { Staphylococcus } \\
\text { Neisseria } \\
\square \text { Veillonella } \\
\text { Other }\end{array}$ & $\begin{array}{l}\text { Enterococcus } \\
\text { Kocuria } \\
\text { Rothia }\end{array}$ & $\begin{array}{l}\text { Microbacterium } \\
\text { Actinomyces } \\
\text { Shigella }\end{array}$ \\
\hline
\end{tabular}
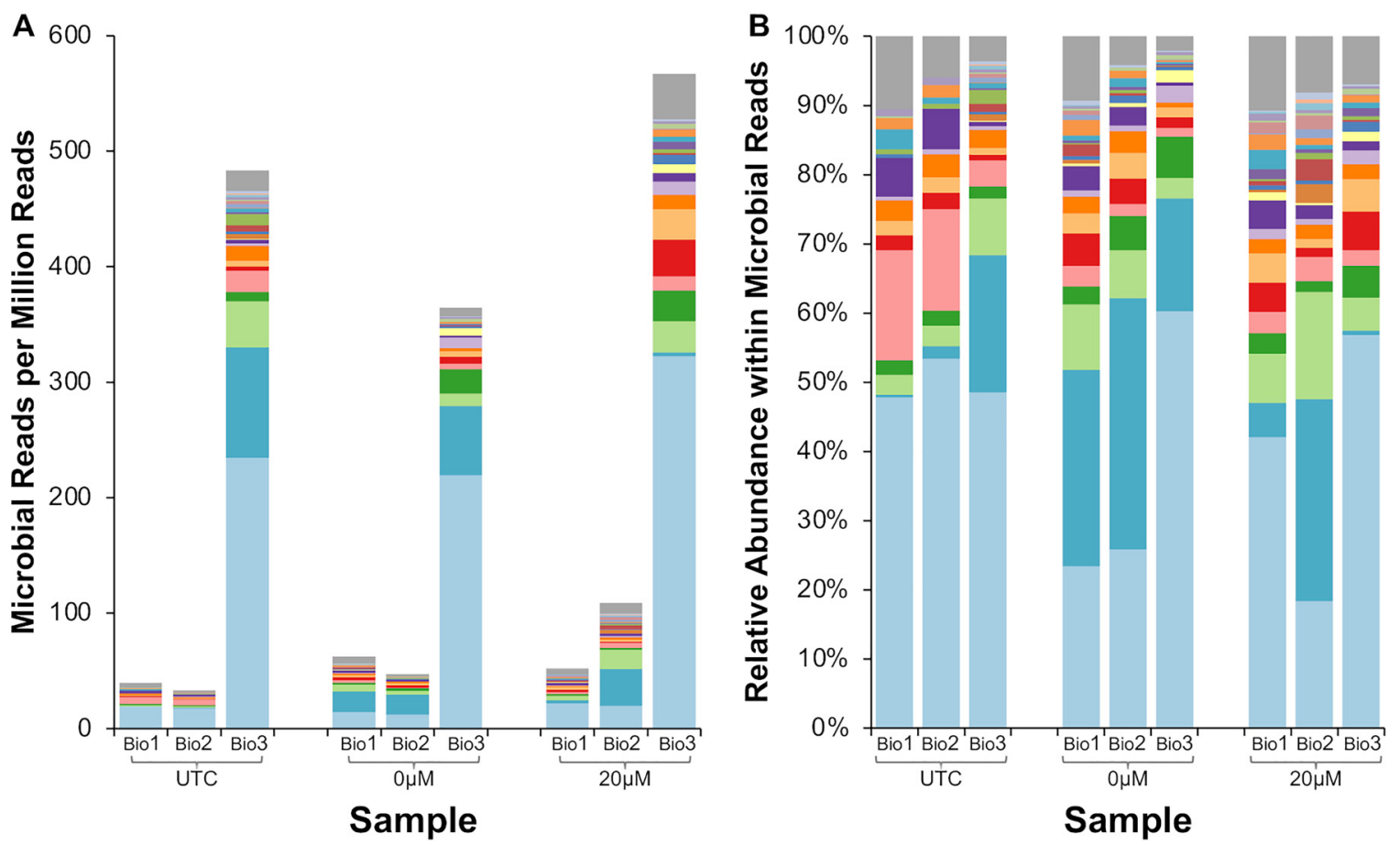

FIG 5 Microbial profile of samples exposed to osmotic lysis and PMA treatment. (A) Microbial reads per million reads by biological sample and treatment. (B) Relative abundance within microbial reads by biological sample and treatment. UTC, untreated control sample; $0 \mu \mathrm{M}$, milk that underwent osmotic lysis but was not treated with PMA; $20 \mu \mathrm{M}$, milk that underwent osmotic lysis and PMA treatment at $20 \mu \mathrm{M}$.

applicable to raw milk, we tested a lysis protocol that included a mild protease, with the objective of more efficiently permeabilizing mammalian cells while keeping bacterial cells intact. Because we were aware of potential biases that could be introduced by adding an enzymatic lysis step prior to PMA treatment, we decided to inoculate the samples tested with Gram-positive and Gram-negative bacteria to address potential differential bacterial permeabilization by subtilisin that would result in DNA inactivation by PMA binding. We also investigated whether the light source would have an effect on the efficiency of PMA binding by processing samples in parallel and exposing PMA-treated sample duplicates to either a halogen light source or a commercial apparatus designed for use with PMA-treated samples (BLU-V; Qiagen). We prepared two biological replicates with two technical replicates for each comparison, from which duplicate qPCRs were done.

Treatment with subtilisin decreased the number of culturable bacteria as assessed through CFU plate counts of milk that had been treated with lysis solution prior to PMA exposure (Fig. 7A) $(P<0.001)$. However, we did not observe a difference in CFU counts in milk samples treated with different enzyme concentrations. The light source did not affect copy numbers $(P=0.74)$; therefore, qPCR comparisons were performed

TABLE 4 Host DNA depletion kit characteristics

\begin{tabular}{|c|c|c|c|}
\hline Abbreviation & Kit & Method & Catalog no. \\
\hline NEB & NEBNext microbiome DNA enrichment & Methylated host DNA capture & E2612 \\
\hline Qia & QIAamp DNA microbiome & Host DNA degradation with Benzonase & 51704 \\
\hline Molz & Molzym ultra-deep microbiome prep & Host DNA degradation with MolDNaseB & G-020-025 \\
\hline
\end{tabular}

${ }^{a}$ Not a commercial kit but an in-house protocol combining selective lysis and exposure to PMA and light. 
TABLE 5 Descriptive statistics of log numbers of copies per milliliter of milk for host depletion

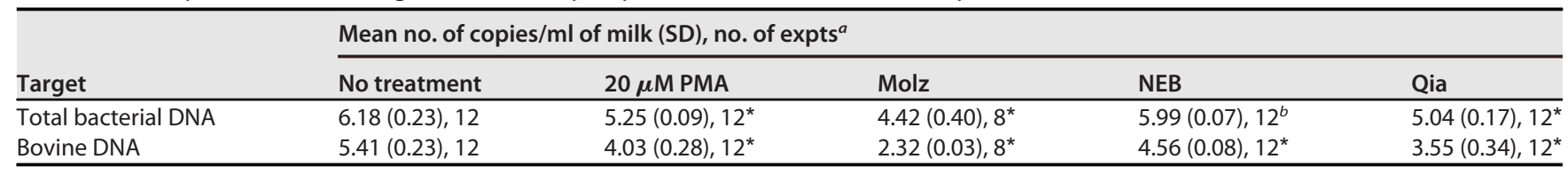

${ }^{a}$ Asterisks represent a significant difference from the values for the no-treatment control (Tukey-adjusted $P<0.0001$ ).

${ }^{b}$ Bacterial copy numbers were significantly different from those of the no-treatment control (Tukey-adjusted $P=0.0532$ ).

with combined data from both the halogen light source and BLU-V apparatus for Fig. 7B. As expected, we observed a decrease in bovine copy numbers in subtilisinPMA-treated samples compared to those in the negative control that was much greater in extent than what we observed with osmotic lysis (Fig. 7B, first segment) $(P=$ 0.04). However, we also observed a dose-dependent decrease in Gram-negative copy numbers in treated samples in the first replicate and were unable to detect Salmonella copy numbers at the higher enzyme concentration in the second replicate (Fig. 7B, third segment), while no differences were observed in Gram-positive copy numbers (Fig. 7B, second segment) $(P=0.3)$. This trend was confirmed by a less steep but still no-
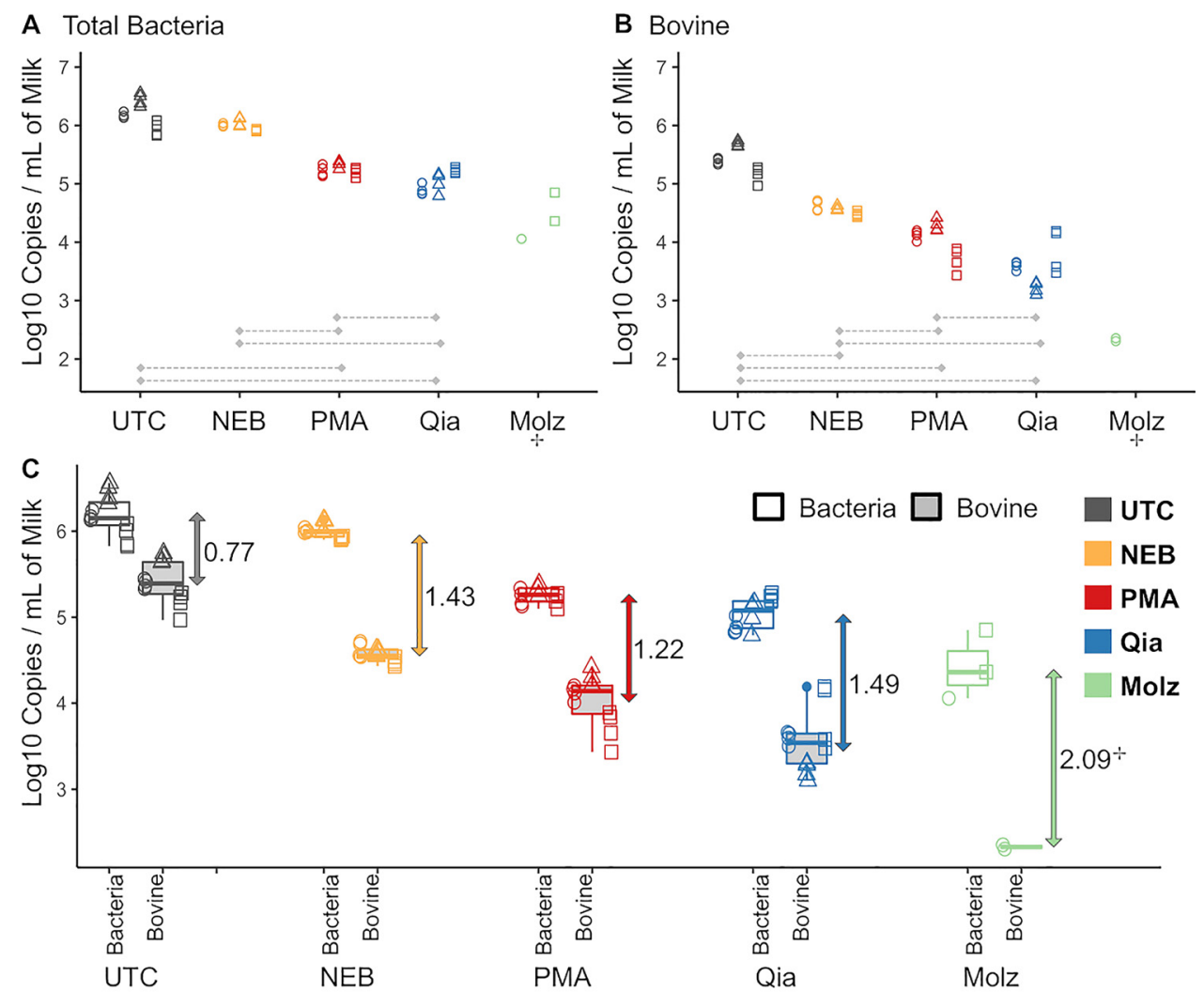

Host Depletion Method and Target

FIG 6 Comparisons of host depletion methods in uninoculated milk. (A and B) Scatterplots of normalized log copy numbers per milliliter of milk obtained with different host depletion methods for total bacterial copy numbers (A) and bovine DNA copy numbers (B). Gray bars represent pairwise significant differences at the 0.05 level after Bonferroni multiple-comparison adjustment in a linear model that included the host depletion method, biological replicate, and their interaction. Scatterplot shapes represent each of three independent biological replicates (circles, first; triangles, second; and squares, third), whereas colors represent methods evaluated. (C) Paired boxplots represent normalized log copy numbers per milliliter of milk from three independent experiments with two technical replicates each, except with the Molzym experiment, which had technical replicates performed on only 1 day. Numbers represent the log difference between mean log bacterial copy numbers and mean log bovine DNA copy numbers. +, technical replicates were performed on only 1 day due to the sample becoming an insoluble pellet during processing; therefore, this method was not included in comparisons. Qia, Qiagen; Molz, Molzym. 


\section{Inoculated Milk}

Enzymatic Treatments

Aerobic Count

\section{A Colony Forming Units}

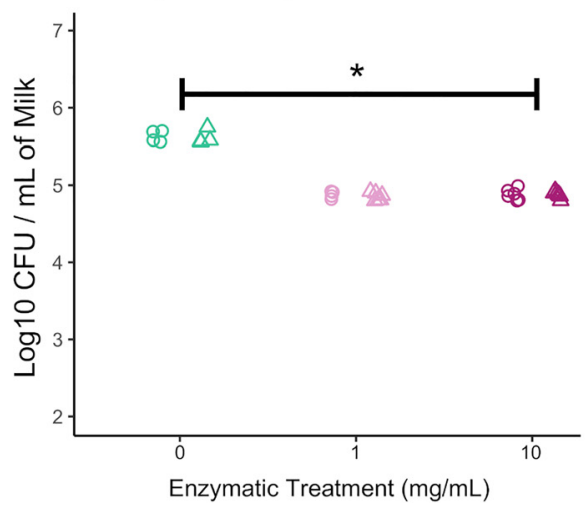

PMA exposure and qPCR

B DNA Copy Numbers

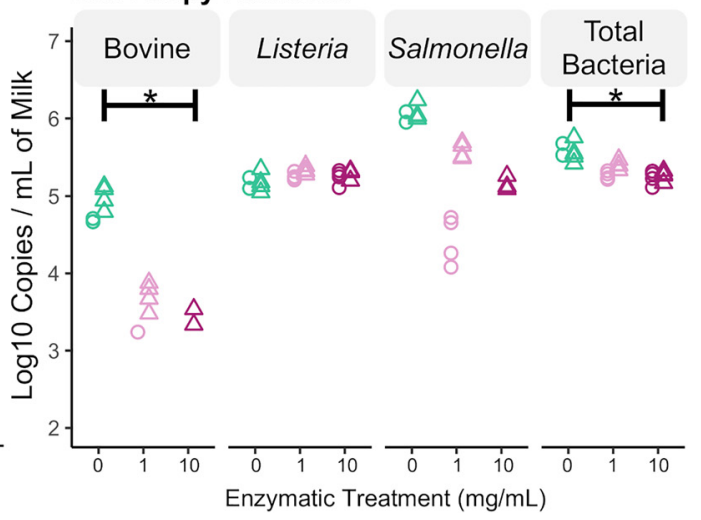

FIG 7 Comparison of enzymatic lysis results prior to host DNA depletion with $20 \mu \mathrm{M}$ PMA in inoculated milk. (A and B) Aerobic standard plate count results (A) and qPCR results (B). Asterisks represent significant differences at a $P$ of $<0.05\left(^{*}\right)$ in linear-model comparisons. Different shapes correspond to two independent experiments with two technical replicates each, from which duplicate GPCRs were done, and colors correspond to the concentrations tested. CT values of samples in which melt curves did not match standard samples' peaks were not used.

ticeable decrease in total bacterial copy numbers compared to the decrease in Gramnegative copy numbers (Fig. 7B, fourth segment) $(P=0.001)$. These data led us to conclude that enzymatic treatment followed by PMA inactivation differentially affects Gram-negative bacterial copy numbers, leading to biased results if used to prepare DNA for sequencing purposes.

\section{DISCUSSION}

In this study, we comprehensively evaluated both nucleic acid extraction and host depletion protocols for bovine raw milk. The rationale of using raw milk as a model included the recent publication of several studies highlighting the variability of raw milk microbiotas (34-36), the potential influence of raw milk microbial quality on processed dairy products (37-39), and the fact that patterns of the milk microbiome represent potential "biomarkers" that can be tracked $(20,21)$. All of these studies highlight milk as a potential candidate for using HTS as part of quality assurance and risk assessment in the food industry in the future. Our results indicate that the following magnetbased DNA extraction methods are superior for extracting DNA from milk. Although host DNA depletion methods decrease the amount of bovine DNA in a given sample, the reduction is not sufficient for effectively depleting bovine DNA in HTS studies of raw milk. We also observed potential for bias introduction by certain protocols on the overall microbial profile, as well as selective bias against Gram-negative bacteria.

Magnet-based DNA extraction seems to provide better results than columnbased methods for raw milk samples. We compared several nucleic acid extraction protocols used on bovine raw milk. While all protocols evaluated for extraction of DNA were able to successfully extract (albeit small amounts of) total DNA, we observed higher variability in replicates in some protocols than in others. The low DNA concentration from milk extracts is in agreement with those of previous reports $(25,26,40)$. One particular aspect of this study is that we inoculated different types of bacteria that would be of interest in a dairy processing environment into raw milk and performed targeted qPCR to assess differential extraction of Gram-positive and Gram-negative bacteria. While most protocols were able to successfully extract DNA from the bacteria inoculated, magnet-based DNA extraction approaches had the best recovery and the 
lowest interreplicate variability, as evaluated by qPCR. It must be noted that the differences observed in the recovery of bacterial DNA are a characteristic of processing steps rather than a flaw or a sign of the inefficiency of a given protocol (i.e., while some extraction methods carry the entire sample lysate from one step to the following, some protocols require fixed or maximum volumes to be transferred to the next step due to volume limitations in the reaction tubes used). It is important to highlight that different DNA extraction methods have advantages and drawbacks, which can also vary according to the material to which they are applied. As no general gold standard method exists to date for this application, the selection of an extraction method should be based on the objectives of each particular study (41). Nevertheless, there is a growing consensus on the importance of mechanical disruption, such as bead beating for microbiome applications (42), and magnet-based extractions have been demonstrated to be particularly effective in the diagnosis of tuberculosis in the sera and plasma of patients (43) and in the extraction of algal DNA for next-generation sequencing (NGS) studies (44), highlighting magnetic methods as a common theme around diverse nucleic acid-based applications.

Extracting bacterial RNA from high-quality raw milk is challenging. The methods used here copurify both DNA and RNA or each nucleic acid separately, and based on the inoculation of bacterial loads in some cases exceeding regulatory standards for raw milk, we expected bacterial RNA to be detectable. We observed very low concentrations of extracted DNA and were unable to successfully detect bacterial RNA from our inoculated milk samples. This was a surprising finding, as literature on the milk metatranscriptome is available (19). However, the protocols previously used to successfully isolate RNA from milk involved extensive centrifugation of large sample volumes followed by several wash steps (45), as well as samples with much greater bacterial loads, including dairy products (such as cheese), which contain high levels of organisms responsible for fermentation of the products $(19,21)$.

Current methods for host DNA depletion are not suitable for application in untargeted HTS studies of milk. Because the bovine cells are present in milk along with the microbes of interest, and due to the striking difference between bovine and bacterial genome sizes, developing efficient yet unbiased host DNA depletion methods is critical for the adoption of HTS technologies in food safety. While we observed a decrease in the number of bovine copies compared to bacterial copies as assessed through qPCR in all protocols evaluated, this decrease is not sufficient to effectively change the relative abundance of reads being assigned to the bovine genome in HTS studies. This was confirmed when we performed deep untargeted sequencing of a subset of samples that had demonstrated promising results in QPCR but still detected over 99\% of reads mapping to the bovine genome independent of host DNA depletion.

Among the other host DNA depletion protocols evaluated were immunoprecipitation of methylated eukaryotic DNA and selective lysis of mammalian cells followed by DNase treatment. One reason for the lack of efficiency observed in the treatment of milk with either of these methods may be the challenges associated with extracting DNA from milk in the first place. Such protocols require large amounts of good-quality DNA, which is practically impossible to obtain from milk samples without extensive centrifugation and pellet washes, potentially proving impractical in industry settings and representing added opportunities for sample contamination or unintentional bias of the microbiota for lipid- or protein-bound microorganisms. The characteristics of milk by themselves can also pose a challenge (presence of fats, proteins, and ions) (8, 9). Challenges specific to nucleic acid extraction from milk have been discussed in the literature to some extent, specifically by Metzger et al., who reported challenges in amplifying bacterial DNA from DNA extracted from milk (46).

To the best of our knowledge, this was the first study to evaluate host DNA depletion methods in a food matrix. The literature that tries to address host contamination in clinical sequencing applications for pathogen detection is limited, although improvements in the detection of malaria (47) and pathogens in infected tissue samples (48) and sputum (32) have been reported. Reports describing attempts to use host 
DNA depletion in cerebrospinal (30) and arthroplasty (29) fluids, as well as human saliva (28), are also available. The common theme around these studies was the various efficiencies across methods and sample types, highlighting the need for individual assessment of host depletion methods using the desired sample type.

Enzyme-based selective lysis followed by PMA treatment differentially affects Gram-negative bacteria in inoculated raw milk. Propidium monoazide has been extensively used to differentiate between live and dead bacterial cells due to its inability to penetrate intact cell membranes and has recently been indicated to be an effective method for host DNA depletion for use in HTS studies $(28,49,50)$. We thus developed an enzyme-based method for host DNA depletion (which utilized a mild protease) combined with subsequent PMA treatment in an effort to better lyse mammalian cells while retaining intact bacterial cells.

While we detected an effect of the enzymatic treatment on total bacterial numbers as measured through plate counts that appeared to be independent of enzymatic concentration, we did not observe a decrease in Gram-positive bacterial numbers as measured by qPCR after PMA exposure. Nevertheless, in our spiking experiments, we observed an enzyme dose-dependent decrease of Gram-negative copy numbers in samples that underwent selective lysis followed by PMA exposure. These data led us to conclude that enzymatic treatment might have differentially permeabilized the membranes of Gram-negative cells, allowing PMA to bind to DNA without observable differences in overall bacterial survival. Taken together, these observations suggest that potential biases may occur against detection of Gram-negative bacteria through qPCR by this method.

It is imperative to optimize protocols for samples with different characteristics. The generalizability of this study lies in the importance of the standardization and validation of methods for each specific food matrix. It is also important to highlight the challenges associated with low bacterial biomass samples and the fact that various foods have a wide range of biomasses, from very low microbial content in raw milk to relatively high microbial content in some cultured dairy products. Efforts to standardize and recommend best practices in HTS studies, particularly pertaining to low-biomass samples (51-53), have recently begun and must be continued.

Conclusions. Our results suggest that magnet-based extraction methods are superior for bacterial nucleic acid isolation from bovine milk. Host DNA remains a challenge for untargeted sequencing of milk, highlighting that the food matrix characteristics should always be considered whenever planning HTS studies. Enzymatic-lysis-based PMA host depletion introduced dose-dependent biases against Gram-negative bacteria, suggesting that selective lysis permeabilized Gram-negative organisms to PMA, which subsequently hindered our ability to detect Gram-negative bacteria through qPCR without affecting counts of live bacteria. While it is not possible to test all methods available at any given time, we focused on kits and protocols that have been the most widely used for the extraction of nucleic acids from milk. As procedures are improved or new methods are developed, a reevaluation of available protocols would prove useful, as the development of HTS-based tools to aid and improve quality assurance and food safety programs continues to hold great promise.

\section{MATERIALS AND METHODS}

Comparison of nucleic acid extraction protocols in spiked milk. (i) Strain selection. We selected a Gram-positive bacterium (Listeria monocytogenes), a Gram-negative bacterium (Salmonella enterica), and a sporeformer (Bacillus wiedmannii) previously isolated from milk or the dairy environment to create a mock microbial community that would be inoculated into raw milk. We included an additional Gram-positive bacterium, a member of the Mycobacteriaceae family (Mycobacterium smegmatis), because of the potential public health implications and the uniqueness of the cell structure of mycobacteria. Milk samples were specifically inoculated with Salmonella enterica, Listeria monocytogenes, and Mycobacterium smegmatis vegetative cells grown to stationary phase and Bacillus wiedmannii spores. Specific strain information is available in Table 6 and in the Food Microbe Tracker database (www.foodmicrobetracker.com). The bacterial load of the inoculated milk sample was chosen to represent the largest bacterial concentration allowed for raw milk in the United States, which is 300,000 CFU per ml, in an attempt to simulate the highest legal bacterial load of incoming milk in a dairy processing plant (54). 
TABLE 6 Organisms used in this study

\begin{tabular}{llll}
\hline Target & Isolate & Source & NCBI accession no. \\
\hline Total bacterial DNA/RNA & Pooled culture & & NC_000913 \\
Bacillus wiedmannii & FSL H7-0344 & Pasteurized 2\% milk & NC_004722 \\
Listeria monocytogenes & FSL A5-0145 & Raw milk & NC_003210 \\
Mycobacterium smegmatis & FSL X3-0054 & VanDerVen lab (MC2155) & NC_008596 \\
Salmonella enterica & FSL A5-0218 & Raw milk & NC_003197 \\
Bovine DNA & Bovine blood & Cornell University dairy farm & NM_001037471.2 \\
\hline
\end{tabular}

${ }^{a} \mathrm{NCBl}$ accession numbers of genomes used for primer design. Primers for the detection of the total bacterial

DNA target 16S rRNA gene were designed based on conserved regions of the 16S rRNA gene.

(ii) Inoculum preparation. Bacillus wiedmannii spore suspension was prepared according to Buehler et al. (55). Briefly, the bacterial isolate was streaked from frozen culture into brain heart infusion (BHI) agar (Becton, Dickinson and Co., Sparks, MD) and incubated for $24 \mathrm{~h}$ at $37^{\circ} \mathrm{C}$. Following incubation, a single colony was selected to inoculate a tube containing $5 \mathrm{ml}$ of BHI broth, followed by incubation at $37^{\circ} \mathrm{C}$ for $72 \mathrm{~h}$. Next, $100 \mu$ l of inoculated BHI was spread plated in duplicate on a sporulating medium, AK agar number 2 (Becton, Dickinson and Co.), which was incubated for $120 \mathrm{~h}$ at $37^{\circ} \mathrm{C}$. Sporulation was confirmed via microscopy with a 7.5\% malachite green endospore stain (JT Baker, Phillipsburg, NJ) as detailed in Gaillard et al. (56). Spores were harvested by flooding the agar surface with $10 \mathrm{ml}$ of phosphate-buffered saline (PBS) (Weber Scientific, Hamilton, $\mathrm{NJ}$ ) and scraping the bacterial culture with a cell scraper. Harvested cells were transferred to a sterile centrifuge tube and washed with $10 \mathrm{ml}$ of sterile water three times by centrifugation at 10,500 rpm for $15 \mathrm{~min}$ and resuspension of the pellet. Following the third wash, $5 \mathrm{ml}$ of sterile water and $5 \mathrm{ml}$ of $100 \%$ ethanol (Decon Labs, King of Prussia, PA) were added to the tube, and the pellet was resuspended by vortexing. The bacterial pellet resuspended in 50\% ethanol was incubated for $12 \mathrm{~h}$ at $4^{\circ} \mathrm{C}$ in a rotating platform to eliminate any remaining vegetative cells. After ethanol treatment, the spore suspension was washed another three times with $10 \mathrm{ml}$ of sterile water as described above. The final spore suspension was kept in sterile water at $4^{\circ} \mathrm{C}$ until used for spiking experiments.

Mycobacterium smegmatis cells were streaked from frozen stocks into $\mathrm{BHI}$ agar, followed by incubation at $37^{\circ} \mathrm{C}$ for $48 \mathrm{~h}$. A single colony was used to inoculate a 5 -ml tube containing $\mathrm{BHI}$ broth with $1 \%$ Tween 80 (Fisher Scientific, Hampton, NH, USA), followed by incubation at $37^{\circ} \mathrm{C}$ for $48 \mathrm{~h}$. The final inoculum was prepared by inoculating $100 \mu \mathrm{l}$ of liquid culture onto $100 \mathrm{ml}$ of prewarmed BHI broth with $1 \%$ Tween 80 , followed by incubation at $37^{\circ} \mathrm{C}$ for $72 \mathrm{~h}$. The resulting stationary-phase culture was kept at $4^{\circ} \mathrm{C}$ until it was used to spike milk samples.

Listeria monocytogenes and Salmonella enterica cells were streaked separately from frozen stocks into $\mathrm{BHI}$ agar, followed by incubation at $37^{\circ} \mathrm{C}$ for $24 \mathrm{~h}$. For each strain, a single colony was used to inoculate a $5-\mathrm{ml}$ tube containing $\mathrm{BHI}$ broth, followed by incubation at $37^{\circ} \mathrm{C}$ for $24 \mathrm{~h}$. The final inoculums were prepared by inoculating $100 \mu \mathrm{l}$ of each liquid culture onto $100 \mathrm{ml}$ of prewarmed BHI broth, which was subsequently incubated at $37^{\circ} \mathrm{C}$ for $12 \mathrm{~h}$.

At harvesting, bacteria were spiral plated on agar using an Eddy Jet $2 \mathrm{~W}$ spiral plater (IUL Micro, Barcelona, Spain) at various dilutions to determine bacterial concentrations. Bacterial liquid cultures were kept at $4^{\circ} \mathrm{C}$ until bacterial enumeration (B. wiedmannii, L. monocytogenes, and Salmonella sp. were kept for $24 \mathrm{~h}$, and $M$. smegmatis was kept for $48 \mathrm{~h}$ at $4^{\circ} \mathrm{C}$ ). Inoculum volumes were calculated based on CFU.

(iii) Inoculation of raw milk. Raw milk was collected from the Cornell University Ruminant Center (CURC; Hartford, NY) bulk tank into sterile 10-oz lock tab containers (Capitol Plastics, Amsterdam, NY) and transported on ice to the Milk Quality Improvement Program laboratory in Ithaca, NY. Samples were combined into a single sterile 1,000-ml glass bottle and homogenized by inverting the container 50 times. From that bottle, one aliquot $(1 \mathrm{ml})$ was used to make dilutions and determine the initial bacterial count using a standard plate count (SPC) agar (Millipore Sigma, Burlington, MA), which was incubated for $48 \mathrm{~h}$ at $32^{\circ} \mathrm{C}$. Bacterial enumeration was performed using an automated colony counter (SphereFlash automatic colony counter, IUL Micro, Barcelona, Spain). A second aliquot $(60 \mathrm{ml})$ was transported on ice to the DairyOne laboratory (DairyOne, Ithaca, NY) for determination of somatic cell counts (SCC) and milk contents (fat, protein, lactose, and total solids). The remaining milk was used for inoculation with the strains described above. To allow for interaction between inoculated bacteria and milk components and to mimic conditions similar to those when raw milk is stored in dairy silos, inoculated milk was held at $4^{\circ} \mathrm{C}$ for $24 \mathrm{~h}$ prior to use as starting samples for nucleic acid extraction comparisons.

(iv) Bacterial enumeration of inoculated milk samples. Total bacterial enumeration was performed through serial dilutions of each milk sample in PBS, which was spiral plated in duplicate on standard plate count agar as described above and incubated for $48 \mathrm{~h}$ at $32^{\circ} \mathrm{C}$.

(v) Nucleic acid extraction. Raw (uninoculated) milk samples were processed in parallel with inoculated milk samples for all kits. Additionally, a no-template nucleic acid extraction was carried out as a negative control to assess cross-contamination and potential reagent contamination. As a positive control, a mock bacterial community was created in PBS with the same bacteria described above at the same concentration as the inoculated milk samples; this was included on each extraction plate or run as a control. Inoculated milk samples were extracted in three technical replicates in each of three independent biological replicates, which were performed on separate days with a different raw milk sample used for each biological replicate.

Kits, manufacturers, and protocol details are described in Table 2. For each of the nine protocols evaluated, samples were processed in parallel (uninoculated milk, inoculated milk triplicates, mock 
TABLE 7 Primers used in this study

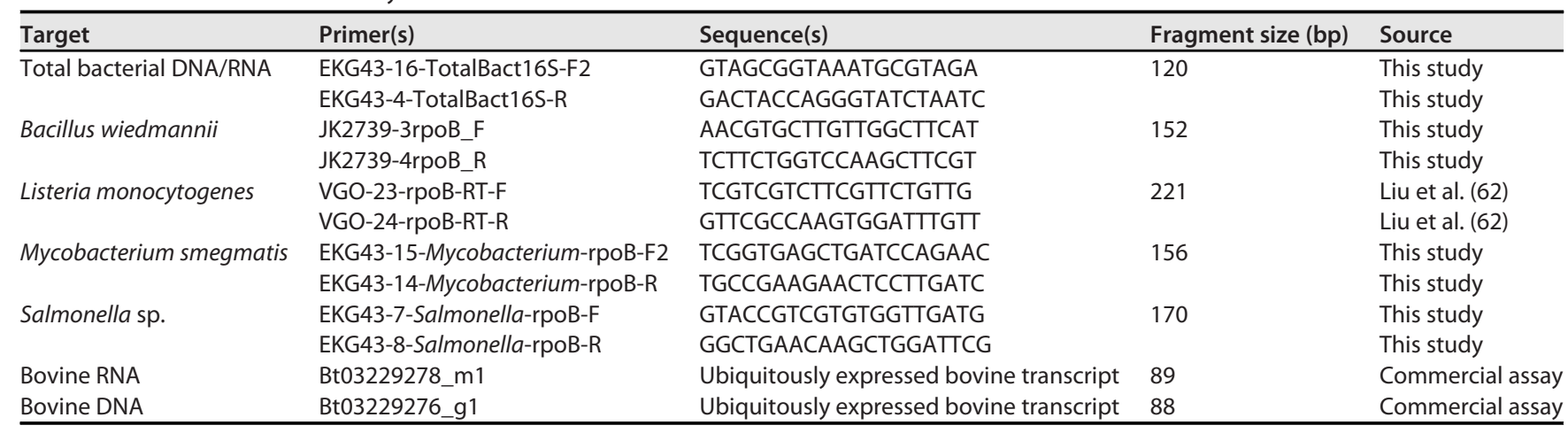

bacterial community in PBS, and a negative control without a starting sample ["kit buffers only"]) according to the manufacturer's instructions. Exact versions of protocols followed can be found in a GitHub repository as supplemental material (https://github.com/ErikaGanda/MilkDNA). Extracted nucleic acids were frozen at $-80^{\circ} \mathrm{C}$ until quantification and $\mathrm{qPCR}$ assays were performed.

(vi) Nucleic acid quantification. Nucleic acid quantification was performed with both a spectrophotometer (Nanodrop 2000; ThermoFisher Scientific) and a fluorescence-based method. Absorbance was measured at 280, 260, and $230 \mathrm{~nm}$ for DNA and RNA. Total DNA was also measured with a Quant-iT double-stranded DNA (dsDNA) high-sensitivity (HS) assay kit (ThermoFisher Scientific); fluorescence measurements were performed using a Synergy H1 plate reader (BioTek Instruments, Winooski, VT, USA) with wavelengths of $490 \mathrm{~nm}$ for excitation and $535 \mathrm{~nm}$ for emission.

(vii) qPCR primer development and assay conditions. For each bacterial strain used to inoculate milk samples, qPCR primers were designed to target the RNA polymerase subunit beta gene (rpoB) because it is a single-copy gene and allows for a more accurate comparison between bacterial numbers than $16 \mathrm{~S}$ rRNA genes. Primers were also designed to target a conserved region of the $16 \mathrm{~S}$ rRNA gene, and calculated $16 \mathrm{~S}$ copy numbers were used as a proxy for total bacterial numbers. Primer details are described in Table 7. Reactions were carried out in duplicate using $2 \mu \mathrm{l}$ of extracted DNA. The final qPCR volumes totaled $25 \mu \mathrm{l}$ and contained $12.5 \mu \mathrm{l}$ SYBR green master mix (ThermoFisher Scientific), $2 \mu \mathrm{l}$ extracted DNA, $0.5 \mu \mathrm{M}$ forward primer, $0.5 \mu \mathrm{M}$ reverse primer, and $9.5 \mu \mathrm{l}$ nuclease-free water. Reactions were carried out in a QuantStudio 6 instrument (ThermoFisher Scientific), with the following cycling conditions: $95^{\circ} \mathrm{C}$ for $10 \mathrm{~min}$ followed by 40 cycles of $95^{\circ} \mathrm{C}$ for $15 \mathrm{~s}$ and $60^{\circ} \mathrm{C}$ for $1 \mathrm{~min}$ and a melting curve of $95^{\circ} \mathrm{C}$ for $15 \mathrm{~s}, 60^{\circ} \mathrm{C}$ for $1 \mathrm{~min}$, and $95^{\circ} \mathrm{C}$ for $15 \mathrm{~s}$.

Bovine genome copy numbers were calculated using a commercial TaqMan assay targeting the UXT gene (ThermoFisher Scientific). The final qPCR totaled $20 \mu \mathrm{l}$ and included $1 \mu \mathrm{l}$ of the gene expression assay mixture, $10 \mu \mathrm{l}$ TaqMan Fast advanced master mix (ThermoFisher Scientific), $7 \mu \mathrm{l}$ of nuclease-free water, and $2 \mu \mathrm{l}$ of the template. Reactions were carried out in a QuantStudio 6 instrument, with the following cycling conditions: $95^{\circ} \mathrm{C}$ for $20 \mathrm{~s}$, followed by 40 cycles of $95^{\circ} \mathrm{C}$ for $1 \mathrm{~s}$ and $60^{\circ} \mathrm{C}$ for $20 \mathrm{~s}$. For each of the three biological replicates, samples extracted with all kits were amplified in a single PCR plate and compared using the same standard curve.

(viii) qPCR data analysis. Amplification data were exported from QuantStudio real-time PCR software (ThermoFisher Scientific) into Excel (version 16.0.11325.20156; Microsoft Corp., Redmond, WA). Standard curves were built with serial dilutions of purified bacterial DNA that was quantified using a Nanodrop spectrophotometer (ThermoFisher), and genome equivalents in each reaction mixture were calculated as described in Brankatschk et al. (57). Standard curves with an $R^{2}$ of $<0.9$ and an efficiency of $<70 \%$ were discarded, and reactions were repeated. For 2 out of 24 reaction plates, one outlier was removed based on visual inspection of deviating standard curve data points.

Copies per microliter of the DNA input were calculated for each reaction. Melt curves were visually inspected, and cycle threshold (CT) values of samples in which melt curves did not match standard samples' peaks were not used for final copy number calculations. Because different kits required various amounts of sample input and nucleic acid output (Table 2), data were normalized to allow for comparison between kit protocols. We chose to simulate copy numbers in $1 \mathrm{ml}$ of milk input and $100 \mu \mathrm{l}$ DNA output for each kit, using the following equations:

$$
\begin{gathered}
\text { milk equivalents }=\frac{\text { input milk sample }(\mu \mathrm{l})}{\text { eluted DNA }(\mu \mathrm{l})} \\
\text { copies } / \mathrm{ml} \text { of milk }=\frac{\text { copies } / \mu \mathrm{l} \text { of DNA } \times 1,000}{\text { milk equivalents }}
\end{gathered}
$$

Normalized copy number data were log transformed prior to statistical analysis. The final data set was cross-referenced and checked with the open-source software OpenRefine (https://github.com/ 
OpenRefine). All statistical analyses with inoculated milk PCR data were performed in R (version 3.4.3; R Project, Vienna, Austria).

(ix) Statistical analysis. To describe the differences observed between extraction methods, linear models were fit using the Im function in R comparing log copy numbers between kits. A separate linear model was fit for each assay, and all linear models included kit/method, biological replicate (SpikeSet), and their interactions. Two observations (one from PowerFood in the Bacillus wiedmannii assay and one from CORE in the total bacterial DNA assay) had Cook's distance greater than 0.5 , were flagged as outliers, and were removed from subsequent analyses. The linear model was then refitted excluding these two observations. For each assay, a two-tailed pairwise comparison of means was performed using the $R$ package multcomp (58). Two kits were removed from these comparisons due to identifiability issues stemming from too few nonmissing observations (too many failed reactions). E.Z.N.A. Food DNA had failed reactions across all assays except the bovine assay, and PowerViral had failed reactions in all of the first biological replicates of the Listeria assay. All $P$ values (combined across the 6 assays) were corrected to achieve an overall family-wise error rate less than or equal to 0.05 using the Bonferroni correction (59). Raw data and code are available in a GitHub repository (https://github.com/ErikaGanda/MilkDNA).

Host depletion protocols. (i) Selective osmotic lysis of host cells and host DNA depletion through PMA treatment of uninoculated raw milk. An osmotic lysis-based host DNA depletion protocol was adapted from Marotz et al. (28). Briefly, $500 \mu \mathrm{l}$ of uninoculated milk were centrifuged at $10,000 \mathrm{~g}$ for $8 \mathrm{~min}$, whey was discarded while fat and pellet were kept in the microcentrifuge tube. Five hundred microliters of sterile double distilled water $\left(\mathrm{ddH}_{2} \mathrm{O}\right)$ were added to the pellet. The tube was vortexed until pellet dissolution, followed by incubation at room temperature for $5 \mathrm{~min}$ to allow for osmotic lysis of mammalian cells. We compared four different concentrations of propidium monoazide (PMA; catalog number 40019; Biotium, Hayward, CA): 10, 20, 40, and $50 \mu \mathrm{M}$. Untreated milk (milk that was not centrifuged or exposed to osmotic lysis) and milk exposed to osmotic lysis but not exposed to PMA were also included in comparisons. To account for biological variation and assess repeatability, experiments were performed in three biological replicates performed on three different days, using a different raw milk sample for each biological replicate.

After incubation at room temperature, the appropriate volume of PMA was added to each tube to achieve desired concentrations, followed by a brief mixing and incubation in the dark (in an aluminum foil-wrapped box) for $5 \mathrm{~min}$ on a rotating platform.

Following PMA incubation in the dark, PMA was inactivated by light exposure. Samples were placed horizontally on ice $<20 \mathrm{~cm}$ from a 500-W halogen light source (Woods halogen work light; Southwire Company LLC, Carrollton, GA, USA). Samples were exposed to light on a rotating platform for $5 \mathrm{~min}$ and frozen at $-80^{\circ} \mathrm{C}$ until DNA extraction with a magnet-based method (MagMAX CORE nucleic acid purification kit; ThermoFisher). Quantitative PCRs and data analysis were performed as described above, with the exception that only bovine DNA and total bacterial copy numbers were quantified, as no bacteria were inoculated in the milk samples used. Linear models were fitted to assess the effect of selective lysis in non-PMAtreated samples (UTC versus treatment with $0 \mu \mathrm{M}$ ) and the effect of PMA concentration on copy numbers.

(ii) Selective enzymatic lysis of host cells and host DNA depletion through PMA treatment of inoculated raw milk. Because milk has more fat, protein, and minerals than saliva, we hypothesized that the 1:1 osmotic lysis included in the protocol adapted from Marotz et al. (28) was not optimal for lysing bovine cells in milk compared to that for lysing human cells in saliva.

We thus also evaluated a combination of a mild lysis solution followed by incubation with two concentrations of subtilisin, a protease from Bacillus licheniformis (Krackeler Scientific; catalog number 45P5380-25MG). The lysis solution contained $7.6 \mathrm{~g} /$ liter sodium carbonate, $8.8 \mathrm{~g} /$ liter sodium bicarbonate, $2.43 \mathrm{~g} /$ /iter disodium EDTA, and $2.71 \mathrm{~g} /$ /iter tetrasodium EDTA. Reagents were solubilized in 1 liter of sterile double-distilled water using a stir plate with a magnetic rotating bar for $6 \mathrm{~h}$, prior to $\mathrm{pH}$ measurement, titration to 9.5 , and filter sterilization with a $0.22-\mu \mathrm{m}$ filter (Corning disposable vacuum filter; Fisher Scientific, Waltham, MA).

Experiments were performed on two separate days with a newly collected milk sample on each day. To access potential lysis biases, we spiked milk with a Gram-positive and a Gram-negative bacterium as described above (L. monocytogenes and Salmonella sp.). Spiked milk samples were treated prior to DNA extraction as follows. Four hundred microliters of inoculated milk was added to $1.6 \mathrm{ml}$ of lysis solution and incubated at room temperature for $5 \mathrm{~min}$ prior to the addition of subtilisin. Two concentrations of subtilisin were tested: $10 \mathrm{mg} / \mathrm{ml}(10 \times)$ and $1 \mathrm{mg} / \mathrm{ml}(1 \times)$ to achieve final concentrations of 0.73 and 0.073 units per reaction mixture, respectively. After addition of the enzyme, samples were incubated at $50^{\circ} \mathrm{C}$ for $5 \mathrm{~min}$ and placed on ice after incubation. Samples were then centrifuged at $10,000 \times g$ for $8 \mathrm{~min}$. The supernatantcontaining lysis solution and enzyme were discarded, and the pellet was resuspended with $400 \mu \mathrm{l}$ of PBS. Treated samples were exposed to PMA at $20 \mu \mathrm{M}$ as described above, photoactivated using two light sources (the halogen lamp described above or the BLU-V system from Qiagen) and stored at $-80^{\circ} \mathrm{C}$ until DNA extraction with a magnet-based method (MagMAX CORE extraction kit; ThermoFisher).

Quantitative PCRs and data analysis were performed as described above, with the exception that bovine DNA, total bacterial copy numbers, L. monocytogenes cells, and Salmonella cells were quantified, as we hypothesized that the lysis solution could affect Gram-negative bacteria differently than Gram-positive bacteria.

(iii) Comparison of host DNA depletion methods in uninoculated raw milk. Based on initial experiments with various PMA concentrations we decided to include $20 \mu \mathrm{M}$ in a comparison with three commercial host DNA depletion kits. Kits, manufacturers, and protocol details are described in Table 4. Samples were processed according to the manufacturer's instructions and frozen at $-80^{\circ} \mathrm{C}$.

For the NEB host depletion method, DNA was extracted with a magnet-based extraction procedure and quantified using a qubit fluorometer (ThermoFisher) prior to methylated host DNA capture reactions. 
Final microbially enriched DNA cleanup was performed using AMPure magnetic beads (Beckman Coulter). Exact versions of protocols followed can be found in our GitHub repository (https://github.com/ ErikaGanda/MilkDNA). Three biological replicates (each with two technical replicates) were prepared using a new sample of raw milk for each biological replicate (except with the Molzym kit, which was performed only with duplicate milk samples in 1 day due to limited available reagent amounts).

Quantitative PCRs and data analysis were performed as described above, with the exception that only bovine DNA and total bacterial copy numbers were quantified, as no bacterium was inoculated in the milk samples used.

(iv) Sequencing. In addition to qPCR, we performed deep untargeted sequencing of a subset of nine samples at the Cornell Biotechnology Resource Center. Briefly, DNA quality control was performed in a fragment analyzer, and sequencing libraries were constructed using a Nextera DNA flex kit (now renamed Illumina DNA Prep; Illumina, San Diego, CA) and 2× 150-bp paired-end sequencing was performed in an Illumina NextSeq500. Sequencing data quality control and in silico host signal removal were performed as previously described $(3,4)$, and microbial data were processed as described in the work of Beck et al. (4). Briefly, adapter removal and quality trimming were performed with TrimGalore (60), and trimmed reads of at least $50 \mathrm{bp}$ in length were classified using Kraken v0.3 (61) against a multieukaryote database of 31 common food ingredients and contaminants, including the bovine reference genome (GCF_000003205.7, Btau_5.0.1) for bioinformatic removal of the host signal. Then taxonomic profiling of samples was completed using Kraken v0.3 against microbial RefSeq genomes as described by Beck et al. (4). A study diagram is presented in Fig. 1.

Data availability. The data sets and $\mathrm{R}$ code are available in our GitHub repository: https://github .com/ErikaGanda/MilkDNA. Raw sequencing reads have been deposited for all 9 sequenced samples into SRA under the BioProject accession number PRJNA667736.

\section{SUPPLEMENTAL MATERIAL}

Supplemental material is available online only.

FIG S1, TIF file, $13 \mathrm{MB}$.

TABLE S1, DOCX file, $0.03 \mathrm{MB}$.

TABLE S2, DOCX file, $0.03 \mathrm{MB}$.

\section{ACKNOWLEDGMENTS}

We thank members of the CURC for allowing us to sample, the VanDerVen Lab for providing us with the Mycobacterium smegmatis MC2-155 strain, the Mann Lab for providing bovine RNA used as a standard, and Rachel Silverman for her comments on the manuscript.

All experimental procedures were carried out at Cornell University, because no animal sampling was necessary for this study and an approved research protocol by the Cornell University Institutional Animal Care and Use Committee was not necessary.

E.G., K.L.B., N.H., B.K., and M.W. are part of the Consortium for Sequencing the Food Supply Chain. We declare that they have no conflict of interest.

This work was supported by the New York State Dairy Promotion Advisory Board (Albany, NY; OSP no. 88975), dairy farmers dedicated to the manufacture of high-quality dairy products. E.G. acknowledges support from the program Science without Borders from the Brazilian government under award number 99999.001336/2013-04.

Conceived and designed the experiments: E.G. and M.W. Performed the experiments: E.G. Performed automated DNA extraction: B.D.C. and R.R.A. Analyzed the data: E.G., K.L.B., N.H., B.K., and J.D.S. Wrote the paper: E.G. Revised the manuscript: E.G., K.L.B., N.H., B.K., L.B.G., M.W., and J.D.S. All authors reviewed the manuscript.

\section{REFERENCES}

1. Tan X, Chung T, Chen Y, Macarisin D, Laborde L, Kovac J. 2019. The occurrence of Listeria monocytogenes is associated with built environment microbiota in three tree fruit processing facilities. Microbiome 7:115. https://doi.org/10.1186/s40168-019-0726-2.

2. Guidone A, Zotta T, Matera A, Ricciardi A, De Filippis F, Ercolini D, Parente E. 2016. The microbiota of high-moisture mozzarella cheese produced with different acidification methods. Int J Food Microbiol 216:9-17. https://doi.org/10.1016/j.ijfoodmicro.2015.09.002.

3. Haiminen N, Edlund S, Chambliss D, Kunitomi M, Weimer BC, Ganesan B, Baker R, Markwell P, Davis M, Carol Huang B, Kong N, Prill RJ, Marlowe CH, Quintanar A, Pierre S, Dubois G, Kaufman JH, Parida L, Beck KL. 2019.
Food authentication from shotgun sequencing reads with an application on high protein powders. NPJ Sci Food 3:24. https://doi.org/10.1038/ s41538-019-0056-6.

4. Beck KL, Haiminen N, Chambliss D, Edlund S, Kunitomi M, Carol Huang B, Kong N, Ganesan B, Baker R, Kawas B, Davis M, Prill RJ, Krishnareddy H, Marlowe CH, Pierre S, Quintanar A, Parida L, Kaufman J, Weimer BC. 2020. Monitoring the microbiome for food safety, and quality using deep 1 shotgun sequencing. bioRxiv 2020.05.18.102574.

5. Jagadeesan B, Gerner-Smidt P, Allard MW, Leuillet S, Winkler A, Xiao $Y$, Chaffron S, Van Der Vossen J, Tang S, Katase M, McClure P, Kimura B, Ching Chai L, Chapman J, Grant K. 2019. The use of next generation 
sequencing for improving food safety: translation into practice. Food Microbiol 79:96-115. https://doi.org/10.1016/j.fm.2018.11.005.

6. Foroutan A, Guo AC, Vazquez-Fresno R, Lipfert M, Zhang L, Zheng J, Badran H, Budinski Z, Mandal R, Ametaj BN, Wishart DS. 2019. Chemical composition of commercial cow's milk. J Agric Food Chem 67:4897-4914. https://doi.org/10.1021/acs.jafc.9b00204.

7. Demeke T, Jenkins GR. 2010. Influence of DNA extraction methods, PCR inhibitors and quantification methods on real-time PCR assay of biotechnology-derived traits. Anal Bioanal Chem 396:1977-1990. https://doi.org/ 10.1007/s00216-009-3150-9.

8. Schrader C, Schielke A, Ellerbroek L, Johne R. 2012. PCR inhibitors-occurrence, properties and removal. J Appl Microbiol 113:1014-1026. https:// doi.org/10.1111/j.1365-2672.2012.05384.x.

9. Bickley J, Short JK, McDowell DG, Parkes HC. 1996. Polymerase chain reaction (PCR) detection of Listeria monocytogenes in diluted milk and reversal of PCR inhibition caused by calcium ions. Lett Appl Microbiol 22:153-158. https://doi.org/10.1111/j.1472-765X.1996.tb01131.x.

10. Soboleva SE, Zakharova OD, Sedykh SE, Ivanisenko NV, Buneva VN, Nevinsky GA. 2019. DNase and RNase activities of fresh cow milk lactoferrin. J Mol Recognit 32:e2777. https://doi.org/10.1002/jmr.2777.

11. DiCenzo GC, Finan TM. 2017. The divided bacterial genome. Microbiol Mol Biol Rev 81:e00019-17. https://doi.org/10.1128/MMBR.00019-17.

12. Zhou S, Goldstein S, Place M, Bechner M, Patino D, Potamousis K, Ravindran P, Pape L, Rincon G, Hernandez-Ortiz J, Medrano JF, Schwartz DC. 2015. A clone-free, single molecule map of the domestic cow (Bos taurus) genome. BMC Genomics 16:644. https://doi.org/10.1186/s12864-015-1823-7.

13. Murphy SC, Martin NH, Barbano DM, Wiedmann M. 2016. Influence of raw milk quality on processed dairy products: how do raw milk quality test results relate to product quality and yield? J Dairy Science 99:10128-10149. https://doi.org/10.3168/jds.2016-11172.

14. Bhatt VD, Ahir VB, Koringa PG, Jakhesara SJ, Rank DN, Nauriyal DS, Kunjadia AP, Joshi CG. 2012. Milk microbiome signatures of subclinical mastitis-affected cattle analysed by shotgun sequencing. J Appl Microbiol 112:639-650. https://doi.org/10.1111/j.1365-2672.2012.05244.x.

15. Kuehn JS, Gorden PJ, Munro D, Rong R, Dong Q, Plummer PJ, Wang C, Phillips GJ. 2013. Bacterial community profiling of milk samples as a means to understand culture-negative bovine clinical mastitis. PLoS One 8:e61959. https://doi.org/10.1371/journal.pone.0061959.

16. Ganda EK, Gaeta N, Sipka A, Pomeroy B, Oikonomou G, Schukken YH, Bicalho RC. 2017. Normal milk microbiome is reestablished following experimental infection with Escherichia coli independent of intramammary antibiotic treatment with a third-generation cephalosporin in bovines. Microbiome 5:74. https://doi.org/10.1186/s40168-017-0291-5.

17. Walsh AM, Crispie F, Daari K, O'Sullivan O, Martin JC, Arthur CT, Claesson MJ, Scott KP, Cotter PD. 2017. Strain-level metagenomic analysis of the fermented dairy beverage nunu highlights potential food safety risks. Appl Environ Microbiol 83:e01144-17. https://doi.org/10.1128/AEM.01144-17.

18. Addis MF, Tanca A, Uzzau S, Oikonomou G, Bicalho RC, Moroni P. 2016. The bovine milk microbiota: insights and perspectives from -omics studies. Mol Biosyst 12:2359-2372. https://doi.org/10.1039/c6mb00217j.

19. Richards VP, Choi SC, Pavinski Bitar PD, Gurjar AA, Stanhope MJ. 2013. Transcriptomic and genomic evidence for Streptococcus agalactiae adaptation to the bovine environment. BMC Genomics 14:920. https://doi.org/ 10.1186/1471-2164-14-920.

20. Wolfe BE, Button JE, Santarelli M, Dutton RJ. 2014. Cheese rind communities provide tractable systems for in situ and in vitro studies of microbial diversity. Cell 158:422-433. https://doi.org/10.1016/j.cell.2014.05.041.

21. De Filippis F, Genovese A, Ferranti P, Gilbert JA, Ercolini D. 2016. Metatranscriptomics reveals temperature-driven functional changes in microbiome impacting cheese maturation rate. Sci Rep 6:21871. https://doi .org/10.1038/srep21871.

22. Geer SR, Barbano DM. 2014. The effect of immunoglobulins and somatic cells on the gravity separation of fat, bacteria, and spores in pasteurized whole milk. J Dairy Sci 97:2027-2038. https://doi.org/10.3168/jds.2013-7629.

23. Caplan Z, Melilli C, Barbano DM. 2013. Gravity separation of fat, somatic cells, and bacteria in raw and pasteurized milks. J Dairy Sci 96:2011-2019. https://doi.org/10.3168/jds.2012-6006.

24. Kirchner B, Pfaffl MW, Dumpler J, Von Mutius E, Ege MJ. 2016. MicroRNA in native and processed cow's milk and its implication for the farm milk effect on asthma. J Allergy Clin Immunol 137:1893-1895.e13. https://doi .org/10.1016/j.jaci.2015.10.028.

25. Volk H, Piskernik S, Kurinčič M, Klančnik A, Toplak N, Jeršek B. 2014. Evaluation of different methods for DNA extraction from milk. J Food Nutr Res 53:97-104.
26. Quigley L, O'Sullivan O, Beresford TP, Paul Ross R, Fitzgerald GF, Cotter PD. 2012. A comparison of methods used to extract bacterial DNA from raw milk and raw milk cheese. J Appl Microbiol 113:96-105. https://doi .org/10.1111/j.1365-2672.2012.05294.x.

27. Lima SF, Bicalho MLS, Bicalho RC. 2018. Evaluation of milk sample fractions for characterization of milk microbiota from healthy and clinical mastitis cows. PLoS One 13:e0193671. https://doi.org/10.1371/journal .pone.0193671.

28. Marotz CA, Sanders JG, Zuniga C, Zaramela LS, Knight R, Zengler K. 2018. Improving saliva shotgun metagenomics by chemical host DNA depletion. Microbiome 6:42. https://doi.org/10.1186/s40168-018-0426-3.

29. Thoendel M, Jeraldo PR, Greenwood-Quaintance KE, Yao JZ, Chia N, Hanssen AD, Abdel MP, Patel R. 2016. Comparison of microbial DNA enrichment tools for metagenomic whole genome sequencing. J Microbiol Methods 127:141-145. https://doi.org/10.1016/j.mimet.2016.05.022.

30. Hasan MR, Rawat A, Tang P, Jithesh PV, Thomas E, Tan R, Tilley P. 2016. Depletion of human DNA in spiked clinical specimens for improvement of sensitivity of pathogen detection by next-generation sequencing. J Clin Microbiol 54:919-927. https://doi.org/10.1128/JCM.03050-15.

31. Oechslin CP, Lenz N, Liechti N, Ryter S, Agyeman P, Bruggmann R, Leib SL, Beuret CM. 2018. Limited correlation of shotgun metagenomics following host depletion and routine diagnostics for viruses and bacteria in low concentrated surrogate and clinical samples. Front Cell Infect Microbiol 8:375. https://doi.org/10.3389/fcimb.2018.00375.

32. Nelson MT, Pope CE, Marsh RL, Wolter DJ, Weiss EJ, Hager KR, Vo AT, Brittnacher MJ, Radey MC, Hayden HS, Eng A, Miller SI, Borenstein E, Hoffman LR. 2019. Human and extracellular DNA depletion for metagenomic analysis of complex clinical infection samples yields optimized viable microbiome profiles. Cell Rep 26:2227-2240.e5. https://doi.org/10 .1016/j.celrep.2019.01.091.

33. Chiu CY, Miller SA. 2019. Clinical metagenomics. Nat Rev Genet 20:341-355. https://doi.org/10.1038/s41576-019-0113-7.

34. Quigley L, O'Sullivan O, Stanton C, Beresford TP, Ross RP, Fitzgerald GF, Cotter PD. 2013. The complex microbiota of raw milk. FEMS Microbiol Rev 37:664-698. https://doi.org/10.1111/1574-6976.12030.

35. Kable ME, Srisengfa Y, Laird M, Zaragoza J, McLeod J, Heidenreich J, Marco ML. 2016. The core and seasonal microbiota of raw bovine milk in tanker trucks and the impact of transfer to a milk processing facility. mBio 7:e00836-16. https://doi.org/10.1128/mBio.00836-16.

36. Doyle CJ, Gleeson D, O'Toole PW, Cotter PD. 2017. Impacts of seasonal housing and teat preparation on raw milk microbiota: a high-throughput sequencing study. Appl Environ Microbiol 83:e02694-16. https://doi.org/ 10.1128/AEM.02694-16.

37. Skeie SB, Haland M, Thorsen IM, Narvhus J, Porcellato D. 2019. Bulk tank raw milk microbiota differs within and between farms: a moving goalpost challenging quality control. J Dairy Sci 102:1959-1971. https://doi.org/10 .3168/jds.2017-14083.

38. Porcellato D, Aspholm M, Skeie SB, Monshaugen M, Brendehaug J, Mellegård H. 2018. Microbial diversity of consumption milk during processing and storage. Int J Food Microbiol 266:21-30. https://doi.org/10 .1016/j.ijfoodmicro.2017.11.004.

39. De Filippis F, Parente E, Ercolini D. 2018. Recent past, present, and future of the food microbiome. Annu Rev Food Sci Technol 9:589-608. https:// doi.org/10.1146/annurev-food-030117-012312.

40. Sun L, Dicksved J, Priyashantha H, Lundh Å, Johansson M. 2019. Distribution of bacteria between different milk fractions, investigated using culture-dependent methods and molecular-based and fluorescent microscopy approaches. J Appl Microbiol 127:1028-1037. https://doi.org/ 10.1111/jam.14377.

41. Ali N, De Cássia R, Rampazzo P, Dias Tavares Costa A, Krieger MA. 2017. Current nucleic acid extraction methods and their implications to pointof-care diagnostics. 2017:1-13.

42. Lim MY, Song EJ, Kim SH, Lee J, Nam YD. 2018. Comparison of DNA extraction methods for human gut microbial community profiling. Syst Appl Microbiol 41:151-157. https://doi.org/10.1016/j.syapm.2017.11.008.

43. Pan S, Gu B, Wang H, Yan Z, Wang P, Pei H, Xie W, Chen D, Liu G. 2013. Comparison of four DNA extraction methods for detecting Mycobacterium tuberculosis by real-time PCR and its clinical application in pulmonary tuberculosis. J Thorac Dis 5:251-257. https://doi.org/10.3978/j.issn .2072-1439.2013.05.08.

44. Fort A, Guiry MD, Sulpice R. 2018. Magnetic beads, a particularly effective novel method for extraction of NGS-ready DNA from macroalgae. Algal Res 32:308-313. https://doi.org/10.1016/j.algal.2018.04.015. 
45. García-Nogales P, Serrano A, Secchi S, Gutiérrez S, Arís A. 2010. Comparison of commercially-available RNA extraction methods for effective bacterial RNA isolation from milk spiked samples. Electron J Biotechnol 13:10. https://doi.org/10.2225/vol13-issue5-fulltext-10.

46. Metzger SA, Hernandez LL, Skarlupka JH, Suen G, Walker TM, Ruegg PL. 2018. Influence of sampling technique and bedding type on the milk microbiota: results of a pilot study. J Dairy Sci 101:6346-6356. https://doi .org/10.3168/jds.2017-14212.

47. Feehery GR, Yigit E, Oyola SO, Langhorst BW, Schmidt VT, Stewart FJ, Dimalanta ET, Amaral-Zettler LA, Davis T, Quail MA, Pradhan S. 2013. A method for selectively enriching microbial DNA from contaminating vertebrate host DNA. PLoS One 8:e76096. https://doi.org/10.1371/journal .pone.0076096.

48. Heravi FS, Zakrzewski M, Vickery K, Hu H. 2020. Host DNA depletion efficiency of microbiome DNA enrichment methods in infected tissue samples. J Microbiol Methods 170:105856. https://doi.org/10.1016/j.mimet .2020 .105856 .

49. Fittipaldi M, Nocker A, Codony F. 2012. Progress in understanding preferential detection of live cells using viability dyes in combination with DNA amplification. J Microbiol Methods 91:276-289. https://doi.org/10.1016/j mimet.2012.08.007

50. Nocker A, Camper AK. 2009. Novel approaches toward preferential detection of viable cells using nucleic acid amplification techniques. FEMS Microbiol Lett 291:137-142. https://doi.org/10.1111/j.1574-6968.2008.01429.x.

51. Sinha R, Abu-Ali G, Vogtmann E, Fodor AA, Ren B, Amir A, Schwager E, Crabtree J, Ma S, Abnet CC, Knight R, White O, Huttenhower C, The Microbiome Quality Control Project Consortium. 2017. Assessment of variation in microbial community amplicon sequencing by the Microbiome Quality Control (MBQC) Project Consortium. Nat Biotechnol 35:1077-1086. https://doi.org/10.1038/nbt.3981.

52. Minich JJ, Sanders JG, Amir A, Humphrey G, Gilbert JA, Knight R. 2019. Quantifying and understanding well-to-well contamination in microbiome research. mSystems 4:e00186-19. https://doi.org/10.1128/mSystems.00186-19.
53. Eisenhofer R, Minich JJ, Marotz C, Cooper A, Knight R, Weyrich LS. 2019. Contamination in low microbial biomass microbiome studies: issues and recommendations. Trends Microbiol 27:105-117. https://doi.org/10.1016/ j.tim.2018.11.003.

54. FDA. 2017. Grade "A" pasteurized milk ordinance. FDA, Silver Spring, MD. https://www.fda.gov/media/114169/download.

55. Buehler AJ, Martin NH, Boor KJ, Wiedmann M. 2018. Psychrotolerant spore-former growth characterization for the development of a dairy spoilage predictive model. J Dairy Sci 101:6964-6981. https://doi.org/10 .3168/jds.2018-14501.

56. Gaillard S, Leguerinel I, Mafart P. 1998. Model for combined effects of temperature, $\mathrm{pH}$ and water activity on thermal inactivation of Bacillus cereus spores. J Food Sci 63:887-889. https://doi.org/10.1111/j.1365 $-2621.1998 . t b 17920 . x$

57. Brankatschk R, Bodenhausen N, Zeyer J, Burgmann H. 2012. Simple absolute quantification method correcting for quantitative PCR efficiency variations for microbial community samples. Appl Environ Microbiol 78:4481-4489. https://doi.org/10.1128/AEM.07878-11.

58. Hothorn T, Bretz F, Westfall P. 2008. Simultaneous inference in general parametric models. Biom J 50:346-363. https://doi.org/10.1002/bimj.200810425.

59. Bonferroni CE. 1936. Teoria statistica delle classi e calcolo delle probabilità. Pubblicazioni del R Istituto Superiore di Scienze Economiche e Commerciali di Firenze, Florence, Italy.

60. Krueger F. 2020. TrimGalore. GitHub https://github.com/FelixKrueger/ TrimGalore.

61. Wood DE, Salzberg SL. 2014. Kraken: ultrafast metagenomic sequence classification using exact alignments. Genome Biol 15:R46. https://doi .org/10.1186/gb-2014-15-3-r46.

62. Liu Y, Orsi RH, Boor KJ, Wiedmann M, Guariglia-Oropeza V. 2017. Home alone: elimination of all but one alternative sigma factor in Listeria monocytogenes allows prediction of new roles for $\sigma$ B. Front Microbiol 8:1910. 